\title{
GUIDE POUR LA CONCEPTION DES DISPOSITIFS DE FRANCHISSEMENT DES BARRAGES POUR LES POISSONS MIGRATEURS
}

\author{
M. LARINIER *
}

\begin{abstract}
RÉSUMÉ
L'auteur rappelle dans cette note les principes de base devant guider le projeteur lors de la conception des ouvrages de franchissement de barrages ou d'obstacles pour les poissons migrateurs. L'accent est mis sur l'importance de la situation et de l'attractivité de ces ouvrages. Les principes de fonctionnement et les critères de dimensionnement des différents types de passes (passes à bassins successifs, passes à ralentisseurs, écluses et ascenseurs) sont évoqués. Dans la dernière partie sont recensés les éléments à prendre en compte lors de l'établissement d'un projet de passe.
\end{abstract}

\section{SUMMARY}

The author outlines in tinis paper the basic principles which can be used as a guide for planning fish passage facilities at dams or obstructions. Special reference is made to the attraction of fishways entrances. Information is presented concerning functional features and design parameters for different types of fish facilities: pool passes, Denil fishways, fish locks and fish lifts. The author has compiled in the last section a list of data required for planning fish facilities.

\section{AVERTISSEMENT}

Ce document tente de situer de façon très concise le problème des passes à poissons dans son ensemble. Il ne prétend pas, malgré quelques exemples, répondre à tous les problèmes concrets qui peuvent se poser, en particulier sur les grands cours d'eau. Le lecteur se reportera, pour plus de détails, aux ouvrages, rapports ou publications - parus ou à paraître - mentionnés dans la suite.

\section{I - généralités sur les passes}

\subsection{Quel est le principe des dispositifs de franchissement?}

Le principe général des dispositifs de franchissement consiste à attirer les migrateurs en un point déterminé du cours d'eau à l'aval de l'obstacle et à les inciter. voire à les obliger à passer en amont, en leur ouvrant une voie d'eau (passes à poissons stricto-sensu) ou en les piégeant dans une cuve et en déversant celle-ci en amont (systèmes de piégeage et de transport).

Les vitesses et les hauteurs de chute dans les passes doivent rester compatibles avec les capacités de nage et de saut des espèces concernées: les passes doivent permettre le passage de tous les poissons et non pas seulement celui des " athlètes ".

II convient aussi de prendre en considération d'autres paramètres, comme la turbulence, l'éclairement, le bruit, etc. qui peuvent influer considérablemént sur le comportement du poisson. II est beaucoup plus délicat de concevoir des ouvrages de franchissement efficaces pour certaines espèces particulièrement exigentes, comme l'alose, que pour d'autres, comme les salmonidés en général. 


\subsection{Quels sont les différents types de passes à poissons?}

Il existe dans le monde une infinité de types de passes qu'il est cependant possible de regrouper en quelques catégories.

La passe dite "rustique " consiste à relier biefs amont et aval par un chenal creusé dans l'une des rives, chenal dont le fond et les parois sont garnis de rugosités ou d'obstacles imitant en quelque sorte un ruisseau naturel. La pente d'un tel ouvrage ne dépasse pas quelques pour cent.

Le type de passe qui a été le plus souvent utilisé est incontestablement la passe à bassins successifs dont le principe consiste à diviser la hauteur à franchir en plusieurs petites chutes formant une série de bassins communiquant entre eux par des déversoirs - minces ou épais -, des orifices ou des fentes verticales. Les bassins jouent un double rôle: zones de repos éventuelles pour les poissons, ils assurent également une dissipation convenable de l'énergie de l'eau transitant dans la passe. II est donc important de dimensionner correctement les bassins ; la dénivellation entre deux bassins successifs est à déterminer en fonction des espèces migratrices considérées.

L'écluse à poissons (ou écluse "Borland ") fonctionne suivant un principe voisin de celui d'une écluse de navigation : les migrateurs sont piégés dans un sas puis éclusés comme le serait un bateau.

D'autres dispositifs consistent à piéger les migrateurs dans une cuve puis à les transporter à l'amont, soit par voie d'eau (s'il existe une écluse de navigation), soit par ascenseur ou funiculaire, soit encore tout simplement par camion.

Dans les échelles à ralentisseurs - ou "Denil", du nom de leur inventeur - sont disposés sur le fond et/ou sur les parois d'un canal à forte pente (jusqu'a $20 \%$ ) des déflecteurs de formes plus ou moins complexes destinés à réduire les vitesses moyennes de l'écoulement.

\subsection{Existe-t-il un type de passe plus efficace que les autres?}

II n'existe pas de type de passe plus efficace que tous les autres. L'expérience montre que de nombreuses passes à bassins, à ralentisseurs, de même que des ascenseurs se sont également révélés efficaces - ou inefficaces. Le point le plus délicat dans la conception d'un dispositif de franchissement est en effet moins le choix du type de passe - il existera souvent plusieurs solutions susceptibles de donner satisfaction - que la nécessité d'attirer tous les migrateurs vers son entrée le plus rapidement possible lorsqu'ils arrivent sur l'obstacle.

L'attractivité d'un dispositif de franchissement est liée à la situation de l'entrée et aux conditions hydrodynamiques (débits, vitesses, lignes de courants) au voisinage de cette entrée, qui ne doit être masquée ni par des écoulements provenant des turbines ou des ouvrages évacuateurs, ni par des zones de recirculation ou d'eaux mortes.

L'écoulement provenant de la passe doit être décelable par le poisson à partir d'une distance de l'entrée la plus grande possible. C'est pourquoi il est indispensable de créer au niveau de cette entrée des vitesses élevées, vitesses devant cependant rester compatibles avec le passage de toutes les espèces migratrices concernées. On peut adopter comme vitesse minimale au droit de l'entrée une valeur de l'ordre du mètre/seconde, la vitesse optimale pour les salmonidés étant de l'ordre de $2 \mathrm{~m} / \mathrm{s}$

Un soin particulier doit être apporté à la conception de l'entrée d'une passe lors de l'élaboration d'un projet, en particulier sur les grands cours d'eau: on vérifiera que les vitesses à ou aux entrées restent suffisamment élevées pour les différentes conditions du niveau aval susceptibles d'être rencontrées en période de migration.

De façon générale, des vitesses suffisantes peuvent être maintenues en agissant sur les sections d'écoulement (en "pinçant " plus ou moins l'écoulement au niveau de l'entrée) et en modulant le débit dans l'ouvrage de franchissement suivant les conditions de niveau d'eau à l'aval de l'obstacle

\subsection{Comment choisir l'implantation d'une passe?}

Pour un barrage existant - ou un obstacle naturel comme un rapide - il est possible d'observer et de noter le comportement des migrateurs, c'est-à-dire leur route de 
migration, leurs zones de stabulation et les points du barrage où s'effectuent les tentatives de franchissement. Ces indications aideront à choisir la situation de l'entrée de la passe.

Dans le cas d'un ouvrage en projet, on ne peut faire que des hypothèses sur le comportement du poisson et seule l'expérience du projeteur entre en ligne de compte.

Le poisson a tendance à remonter dans le courant le plus à l'amont possible. jusqu'à ce qu'il soit arrêté par une chute d'une hauteur infranchissable ou par des courants ou des turbulences trop violents

En règle générale, il convient donc d'installer l'entrée de la passe le plus près possible du point ou de la ligne de plus haute remontée du migrateur (Fig. 1 et 4).

Dans le cas d'un aménagement hydroélectrique, lorsque tout le débit est turbiné, les migrateurs seront généralement attirés vers les aspirateurs des turbines. II conviendra donc d'installer l'entrée de la passe du côté de l'usine (Fig. 2 et 3).

Il est possible de collecter les poissons sur toute la largeur de l'usine en installant un canal collecteur comportant une série d'entrées au-dessus des aspirateurs des turbines (Fig. 5).

On peut être amené à prévoir non seulement plusieurs entrées, mais aussi plusieurs dispositifs de franchissement différents. Dans le cas d'un aménagement hydroélectrique comportant un barrage de retenue équipé d'ouvrages évacuateurs et un canal de dérivation court-circuitant le cours d'eau sur lequel est implantée l'usine, le migrateur peut se présenter soit du côté de l'usine, au pied des turbines, soit du côté du barrage lorsque celui-ci déverse: il conviendra donc d'envisager deux dispositifs de franchissement totalement indépendants, chacun comportant éventuellement plusieurs entrées.

Le comportement du migrateur n'est pas le seul facteur à considérer dans le choix de l'implantation de la passe : il convient de prendre en compte l'exposition de la passe aux crues, sa protection contre les corps flottants, et son accessibilité de façon à assurer sa surveillance, son contrôle et son entretien. Une passe à poissons est un ouvrage hydraulique, au même titre qu'une prise d'eau, et il est nécessaire d'assurer son entretien, si fastidieux soit-il, faute de quoi elle ne pourra jouer convenablement son rôle.

La protection des passes contre les corps flottants s'effectue par les movens classiques employés sur les ouvrages hydrauliques: drôme flottante, grille à barreaux suffisamment espacés (de 25 a $30 \mathrm{~cm}$ pour permettre le passage des gros migrateurs); on peut utiliser aussi des écrans en maçonnerie ou en béton, des rangées de rails, voire des palplanches battues à l'amont de l'échelle.

Sur les cours d'eau transportant de nombreux arbres ou branches en période de crue, il est important de rendre la passe aisément accessible pour faciliter l'entretien et les réparations. A cet égard, les passes situées en rive sont préférables à celles implantées dans le corps même des déversoirs ou des seuils.

La sortie de la passe (sortie pour le poisson, donc partie amont de la passe) ne doit se trouver ni dans une zone de for te vitesse, à proximité d'un ouvrage évacuateur. (vanne, déversoir) afin que le poisson ne risque pas d'être entraîné de nouveau à l'aval, ni dans une zone d'eau morte ou de recirculation dans laquelle le poisson peut se trouver piégé

\subsection{Quel débit faut-il consacrer au fonctionnement d'une passe à poissons?}

Le dispositif de franchissement doit être à l'échelle du cours d'eau. En particulier, le débit aux entrées du ou des dispositifs de franchissement doit être à l'échelle des débits du cours d'eau en période de migration (de l'ordre de 1 à $5 \%$ ). Il est cependant possible de ne faire transiter qu'une partie du débit par la passe : le débit supplémentaire nécessaire à l'attraction est alors injecté a basse pression (*) dans le tronçon aval de la

(*) Lorsque certaines contraintes liées au site - en particulier sur des ouvrages existants - obligent à implanter l'entrée de la passe en retrait des écoulements principaux, il est possible d'utiliser une fraction du débit d'attrait sans dissipation d'énergie préalable sous forme de jets à fortes vitesses 
passe ou à l'entrée même du dispositif. Cette adjonction de cébit peut se faire par l'intermédiaire d'un diffuseur latéral ou d'un diffuseur de fond (Fig. 6). La vitesse de l'eau à travers les grilles installées en sortie de ces diffuseurs doit rester suffisamment faible $(<0,30 \mathrm{~m} / \mathrm{s})$ par rapport aux vitesses dans la passe de façon à ne pas perturber le comportement du migrateur.

Le débit supplémentaire d'attraction est fourni soit par gravité, après dissipation de l'énergie dans un bassin, soit sur les grosses installations par pompage à partir du bief aval ou par passage dans une ou plusieurs petites turbines spéciales afin de réduire les pertes en énergie.

\subsection{Existe-t-il une passe-type pour un obstacle de caractéristiques données?}

Il serait tentant de ranger les différents obstacles en plusieurs classes - suivant leur hauteur par exemple - et de proposer pour chacune d'elles et en forıction des espèces migratrices un type de passe approprié.

La multiplicité des contraintes et des facteurs (d'ordre biologique, hydrologique. hydraulique, topographique...) fait que chaque situation est un cas d'espèce et l'expérience montre qu'une telle classification rigide est susceptible au contraire d'entraîner de grossières erreurs.

Les quelques points suivants aideront à déterminer pour une situation donnée le type de passe qui convient le mieux.

1.6.1. Des solutions sommaires comme échancrures, passes en écharpe - ou diagonales - (Fig. 7) ou passes en entonnoir - ou goulottes - (Fig. 8) doivent rester limitées

- aux obstacles de faibles hauteurs (1 à 1,50 $\mathrm{m}$ pour les deux premières, 1,50 à $2 \mathrm{~m}$ pour la troisième) devenant aisément franchissables en eaux moyennes ou hautes (*) - aux migrateurs les plus robustes (saumons, truites de mer et, à la rigueur, truites) et cela uniquement lorsque la situation locale rend, pour diverses raisons, la construction d'une passe proprement dite difficile.

Dans le cas de barrage à parement aval vertical, il suffit, pour favoriser le franchissement en eaux basses des espèces qui sautent, d'aménager une brèche permettant d'assurer une lame d'eau d'une épaisseur suffisante. Le poisson ne peut cependant sauter que s'il dispose d'une profondeur d'eau suffisante pour prendre un "appel" au pied de l'obstacle : la présence d'enrochements au pied d'un barrage peut interdire son franchissement par le migrateur

Dans le cas de barrage à parement aval incliné, l'eau s'étale en nappe mince, ce qui peut rendre le passage du poisson impossible en basses eaux. Il suffit généralement d'augmenter par un moyen quelconque l'épaisseur de la lame d'eau - en concentrant le débit - pour rendre l'obstacle franchissable: on utilise soit une écharpe disposée diagonalement sur le parement aval du barrage, soit une goulotte taillée dans ce même parement.

II ne faut cependant pas donner à ce type d'ouvrage une longueur trop importante sous peine d'imposer un effort exagéré au migrateur qui doit le franchir d'une seule traite.

(*) Certains seuils en enrochement, bien que de hauteurs modérées $(1,50$ à 2,50 m) peuvent rester pratiquement infranchissables en eaux moyennes ou hautes dans la mesure où, la chute ne diminuant que très progressivement lorsque le débit augmente, les vitesses et les turbulences au droit du seuil restent incompatibles avec le passage du poisson. II s'agit en particulier de certains seuils, destinés à fixer le lit mineur de cours d'eau déstabilisés suite à des extractions intensives de matériaux alluvionnaires, qui "pincent" l'écoulement de façon à concentrer localement une dissipation d'énergie compensant l'abaissement de la ligne d'eau en aval. 
On peut considérer une vingtaine de mètres comme un maximum à ne pas dépasser pour une écharpe alors qu'on limitera la longueur d'une goulotte à une dizaine de mètres.

Pour ces deux types de passes (écharpe et goulotte), il est essentiel d'éviter les ruptures de pente susceptibles de bloquer le migrateur. Les profils concaves, en particulier ceux créés par les rehaussements de vieux barrages à parement aval incliné, sont particulièrement néfastes aux migrateurs qui se trouvent arrêtés le plus souvent à la cassure de pente existant au niveau de la hausse.

1.6.2. Les passes à ralentisseurs ont une possibilité d'adaptation à une très grande variété de sites. Elles présentent un intérêt particulier:

- pour le saumon et la truite de mer

- pour les obstacles de hauteurs modérées $(<2,50 \mathrm{~m}$ environ)

- pour les ouvrages existants, dans la mesure où il est beaucoup plus facile d'intégrer ce type de passe dans le corps de l'ouvrage qu'une passe à bassins successifs dimensionnée pour un débit identique.

L'installation de ce type de passe perd généralement de son intérêt lorsque la hauteur de l'obstacle à franchir devient plus importante: la nécessité de prévoir des bassins de repos (tous les deux mètres de chute environ) augmente la longueur du dispositif et peut rendre aussi intéressante l'installation d'une passe a bassins successifs.

Certains types de passes à ralentisseurs (ralentisseurs de fond en chevrons épais par exemple) peuvent être utilisés comme glissières à canoë-kayak dans la mesure évidemment où leur largeur le perrret (1,40 m minimum).

1.6.3 Lorsqu'on a affaire à plusieurs espèces migratrices, (saumons, truites de mer, truites, poissons blancs, etc.), la passe à bassins successifs semble être la meilleure solution, moins sélective que la plupart des passes à ralentisseurs.

On distingue quatre types de passes à bassins successifs:

- les passes à parois ou échancrures déversantes,

- les passes à orifices noyés,

- les passes mixtes (parois ou échancrures déversantes et orifices) (Fig. 9),

- les passes à fentes verticales (Fig. 10).

De façon générale, la passe à orifices noyés présente peu d'intérêt. La passe à fentes verticales ne convient que pour les débits importants (supérieurs à $1 \mathrm{~m}^{3} / \mathrm{s}$ environ) et $n$ 'offre d'intérêt que lorsque les fluctuations des niveaux amont et aval sont importantes.

Les passes à bassins à échancrures déversantes, associées ou non à des orifices de fond, sont les plus intéressantes car elles s'adaptent à de nombreux cas de figure (débit disponible de quelques dizaines de litres à plusieurs $\mathrm{m}^{3} / \mathrm{s}$ ) et, dans la mesure où les échancrures sont suffisamment profondes, à des variations du niveau amont relativement importantes.

1.6.4. Pour les ouvrages de hauteurs importantes, l'installation d'un ascenseur (Fig. 13) ou d'une écluse Borland (Fig. 12) est plus facile et beaucoup moins coûteuse que celle d'une passe classique. La complexité de leur fonctionnement (présence de nombreux organes mobiles - vannes, cuves, grilles - automatisés) se traduit cependant par des coûts de maintenance élevés. C'est la raison pour laquelle on peut leur préférer dans certains cas des passes "statiques" d'un génie civil plus coûteux mais d'un entretien moins lourd.

Un ascenseur est généralement préférable à une écluse Borland : le problème de l'attractivité est identique, mais les poissons piégés dans la cuve de l'ascenseur passeront obligatoirement à l'amont, ce qui n'est pas forcément le cas pour les poissons piégés dans la chambre aval d'une écluse Borland là moins de disposer dans le puits 
vertical de l'écluse un carrelet suivant le niveau de l'eau et obligeant les poissons à remonter lorsque l'écluse se remplit).

1.6.5. L'expérience française sur les dispositifs de franchissement pour les aloses est actuellement très limitée. Les quelques observations effectuées sur le Rhône et la Garonne indiqueraient un comportement migratoire très proche de celui de la grande alose d'Amérique du Nord pour laquelle il existe un certain nombre de passes efficaces.

- Les aloses migrent en bancs et il semble important de leur offrir un passage le plus large possible.

- Les entrées principales des dispositifs de franchissement doivent se trouver le long des rives.

- Les aloses éprouvent beaucoup plus de répulsion à s'engager et franchir une passe que les salmonidés. Elles font généralement plusieurs va-et-vient ("fall-back activity") dans le dispositif avant de passer en amont.

- Le meilleur type de dispositif de franchissement pour l'alose est l'ascenseur mécanique dans la mesure où l'on est sûr que les migrateurs passeront en amont une fois attirés au pied du dispositif.

- Lorsque l'obstacle ne se prête pas à l'installation d'un ascenseur, il est préférable. dans l'état actuel des connaissances du comportement de l'alose, d'éviter les passes à ralentisseurs $\left(^{*}\right)$ et de choisir une passe à bassins successifs à parois déversantes, à échancrures latérales ou à fentes verticales, sous réserve des dispositions suivantes:

- Les échancrures et les fentes doivent être suffisamment larges (de l'ordre de 0,40 à $0,50 \mathrm{~m}$ minimum) et situées le long des parois (risque de piégeage des aloses dans les encoignures).

II convient d'éviter la formation de jets plongeants en prévoyant, soit des échancrures en plan incliné assurant un guidage de la lame d'eau, soit des échancrures en mince paroi mais suffisamment noyées par l'aval de telle sorte que l'alose puisse passer d'un bassin à l'autre en nageant dans la lame d'eau.

- Les passes à bassins successifs à orifices noyés se sont avérées de façon générale inefficaces pour l'alose, celle-ci ne cherchant pas à s'engager dans les orifices situés trop en profondeur.

- L'alose ne sautant pas, l'entrée des passes doit se trouver suffisamment immergée de façon que le migrateur puisse y pénétrer en nageant (Cote du fond de l'ouverture d'entrée située à 0,50-0,60 m au-dessous du niveau aval).

- Il convient d'éviter la présence de zones d'eau morte dans tout dispositif de franchissement; en particulier, dans les parties aval des passes susceptibles d'être noyées, on prendra garde à conserver des vitesses suffisantes $(0,30 \mathrm{~m} / \mathrm{s}$ minimum) afin d'inciter le migrateur à passer à l'amont.

${ }^{*}$ ) Bien qu'il existe, aussi bien en France qu'aux États-Unis et au Canada, plusieurs passes à ralentisseurs (ralentisseurs plans ou Lachadenède) empruntées par les aloses, il est difficile de se prononcer de façon objective sur l'efficacité de tels dispositifs pour ces espèces. 


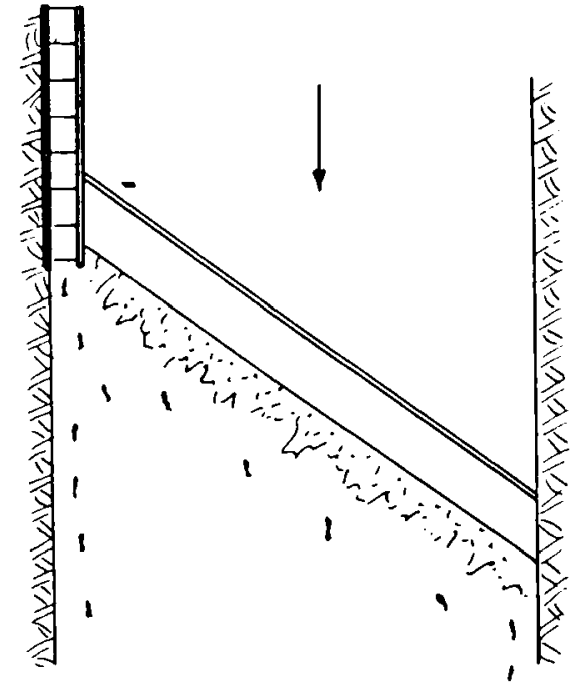

a. Correct (angle amont du déversoir)

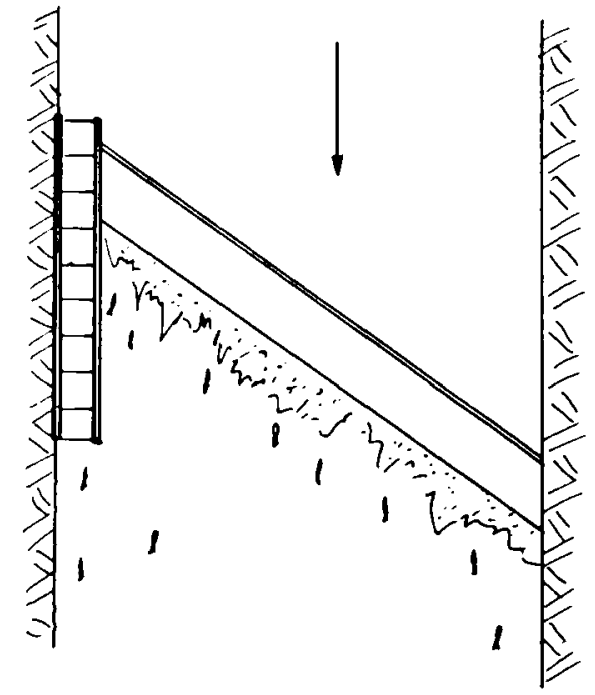

b. Incorrect : entrée située trop en aval

Figure 1 : Implantation d'une passe dans le cas d'un déversoir oblique.

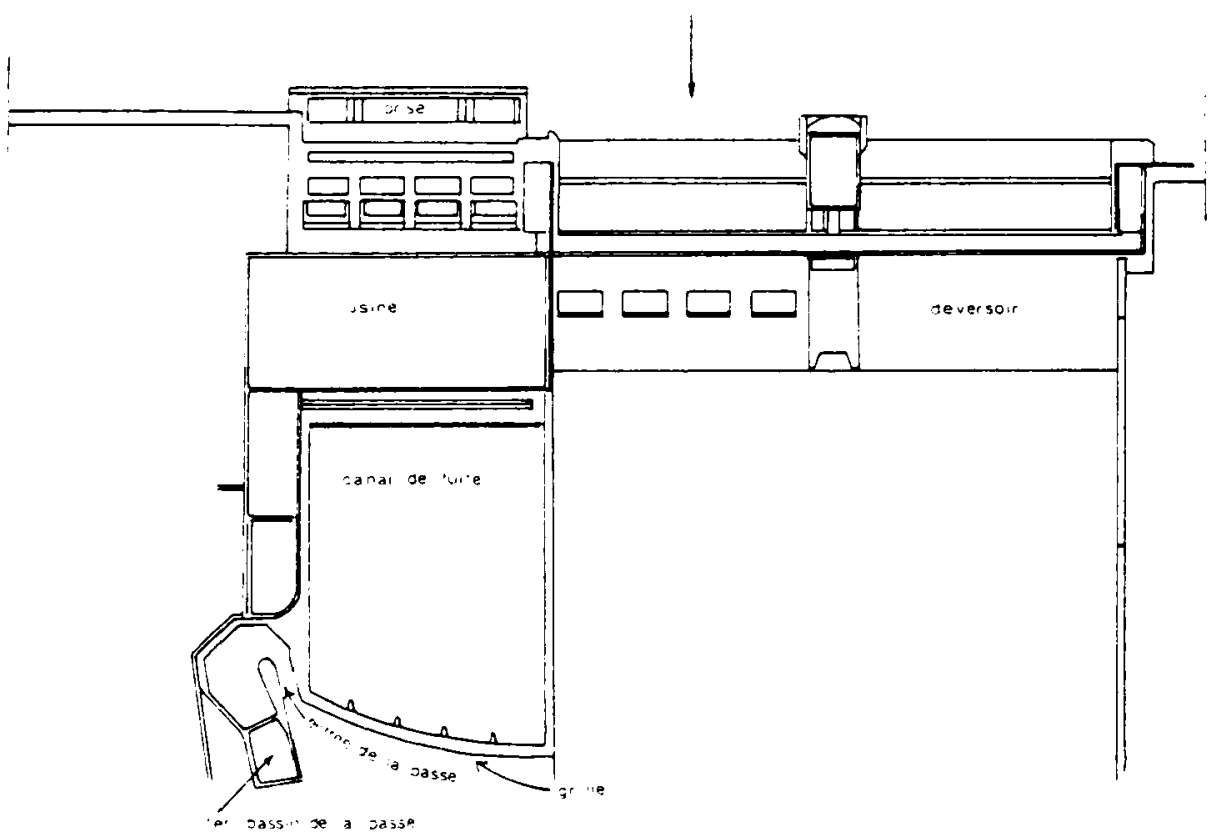

Figure 2 : Implantation d'une passe dans un aménagement hydroélectrique. Exemple de Pitlochry en Écosse. 

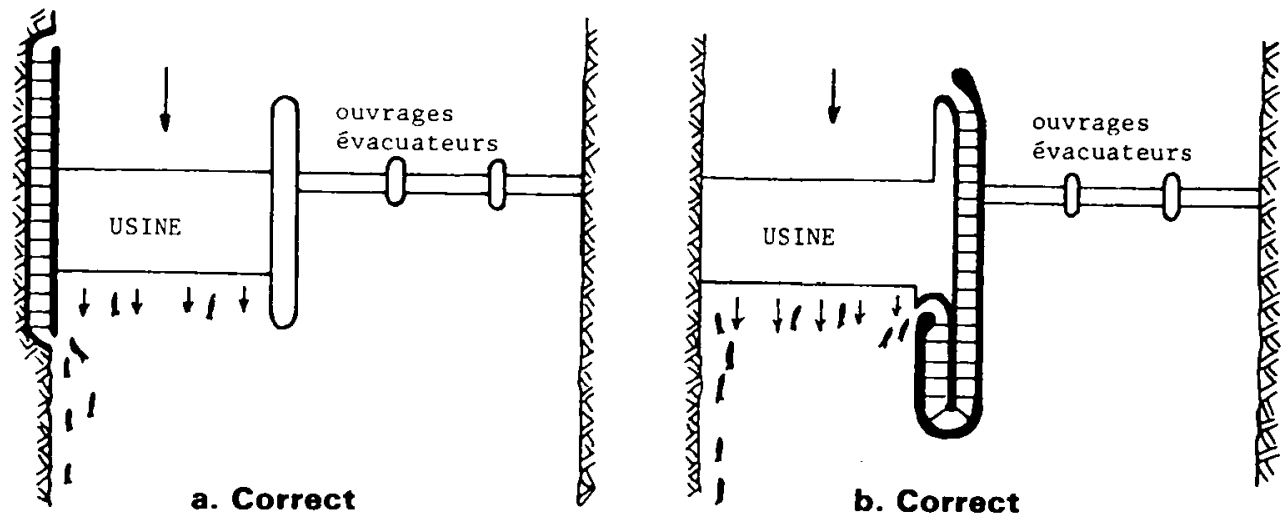

L'entrée doit se situer du côté de l'attrait, c'est-à-dire du côté de l'usine. La situation de l'entrée de la passe en rive est généralement plus favorable qu'au milieu du cours d'eau.

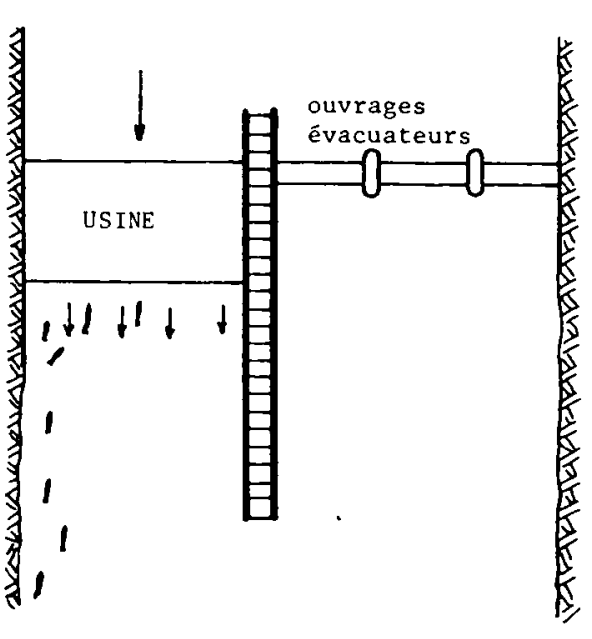

c. Incorrect

(entrée située trop en aval au milieu du cours d'eau)

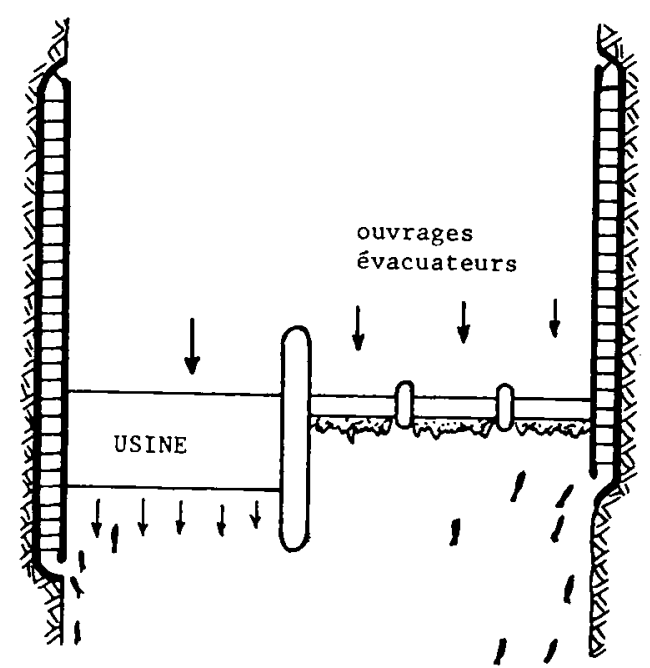

d. Lorsque les organes évacuateurs déversent fréquemment en période de migration, l'installation d'une seconde passe peut s'avérer nécessaire.

Figure 3 : Implantation d'une passe dans le cas d'une usine hydroélectrique 

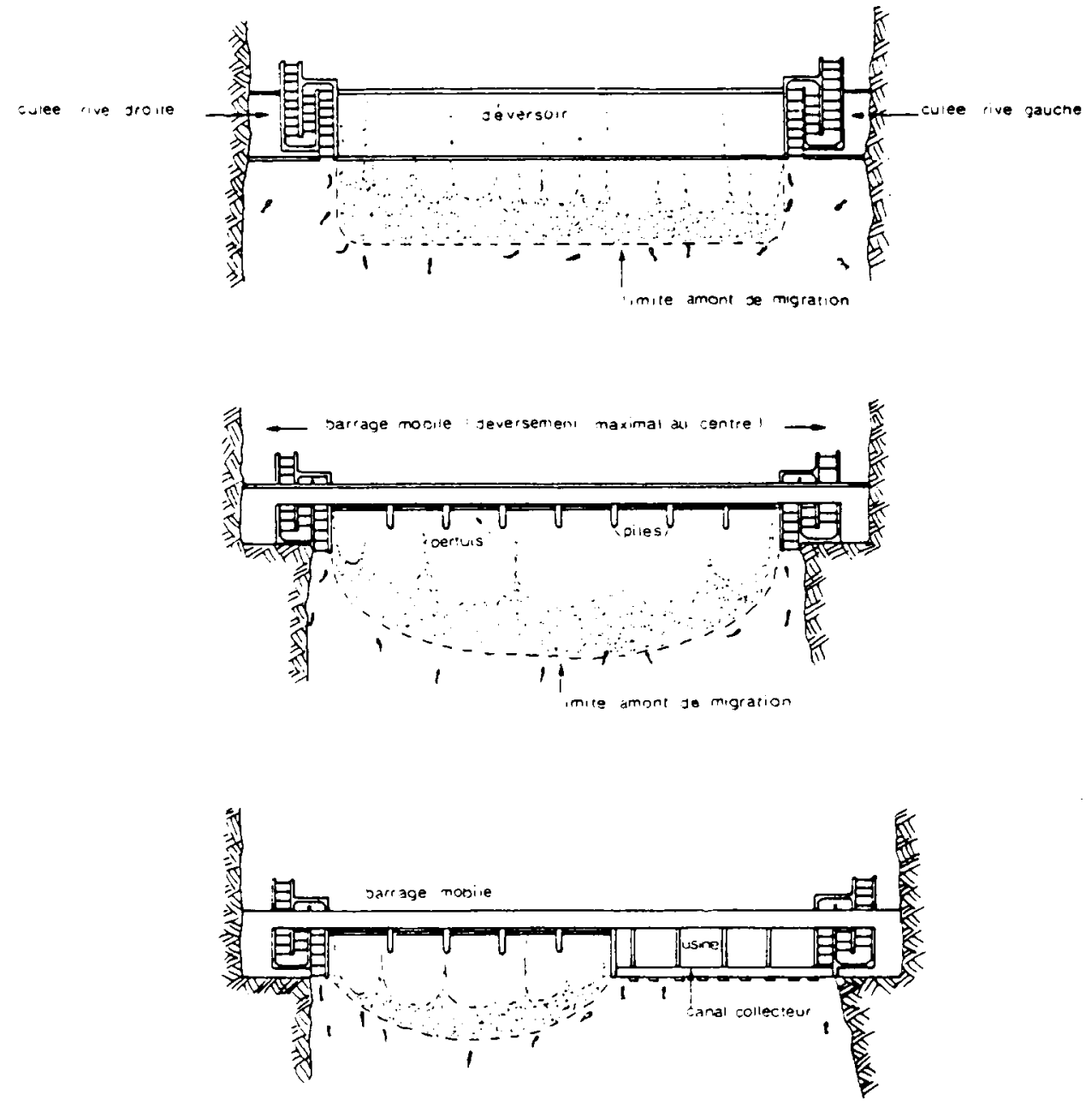

Figure 4 : Schémas montrant l'emplacement des passes dans un déversoir, un barrage mobile et une usine-barrage (d'après CLAY) 


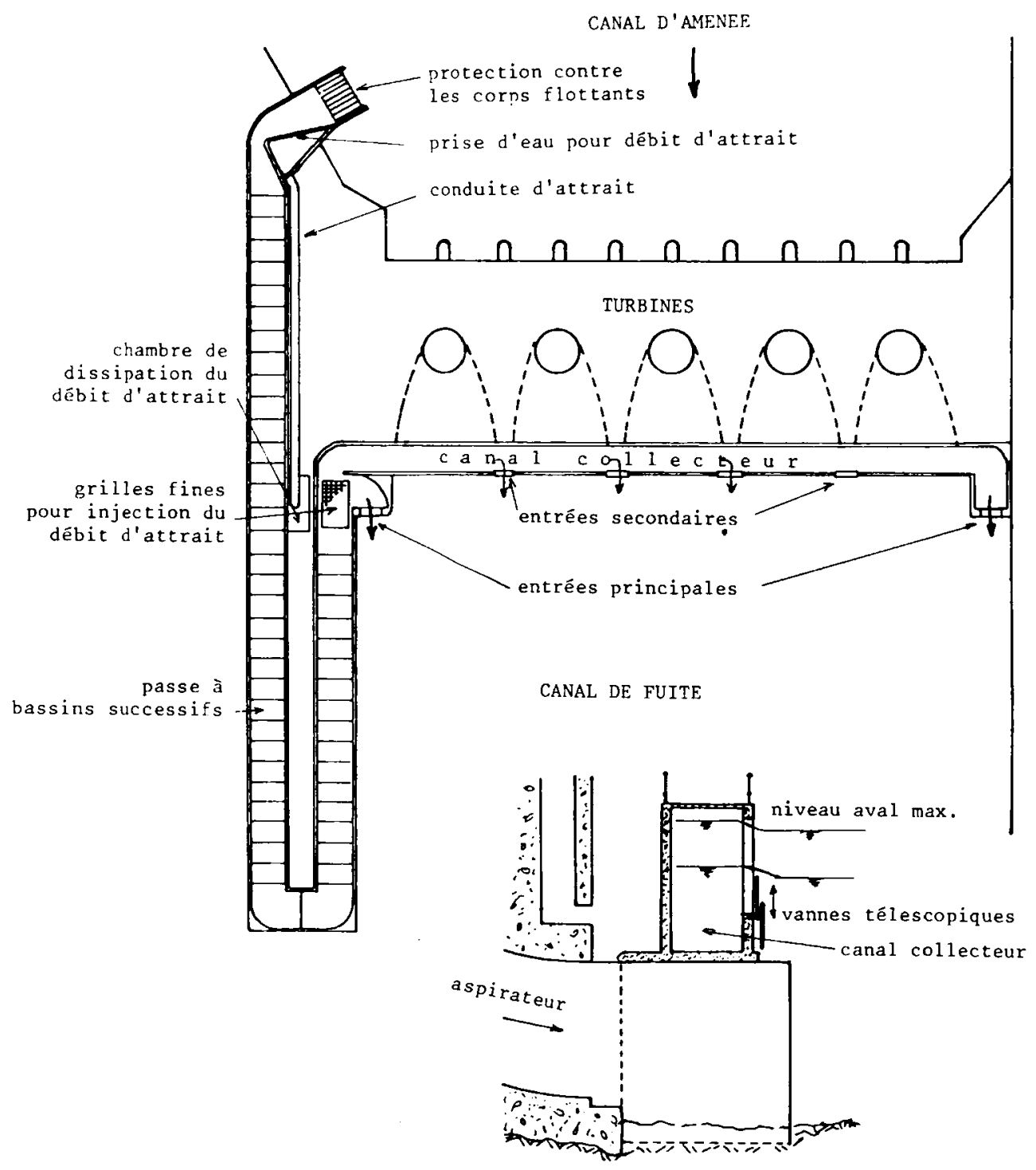

Figure 5 : Principe d'une passe à bassins successifs avec canal collecteur et entrées situées au-dessus des turbines d'une usine hydroélectrique 
$-11-$
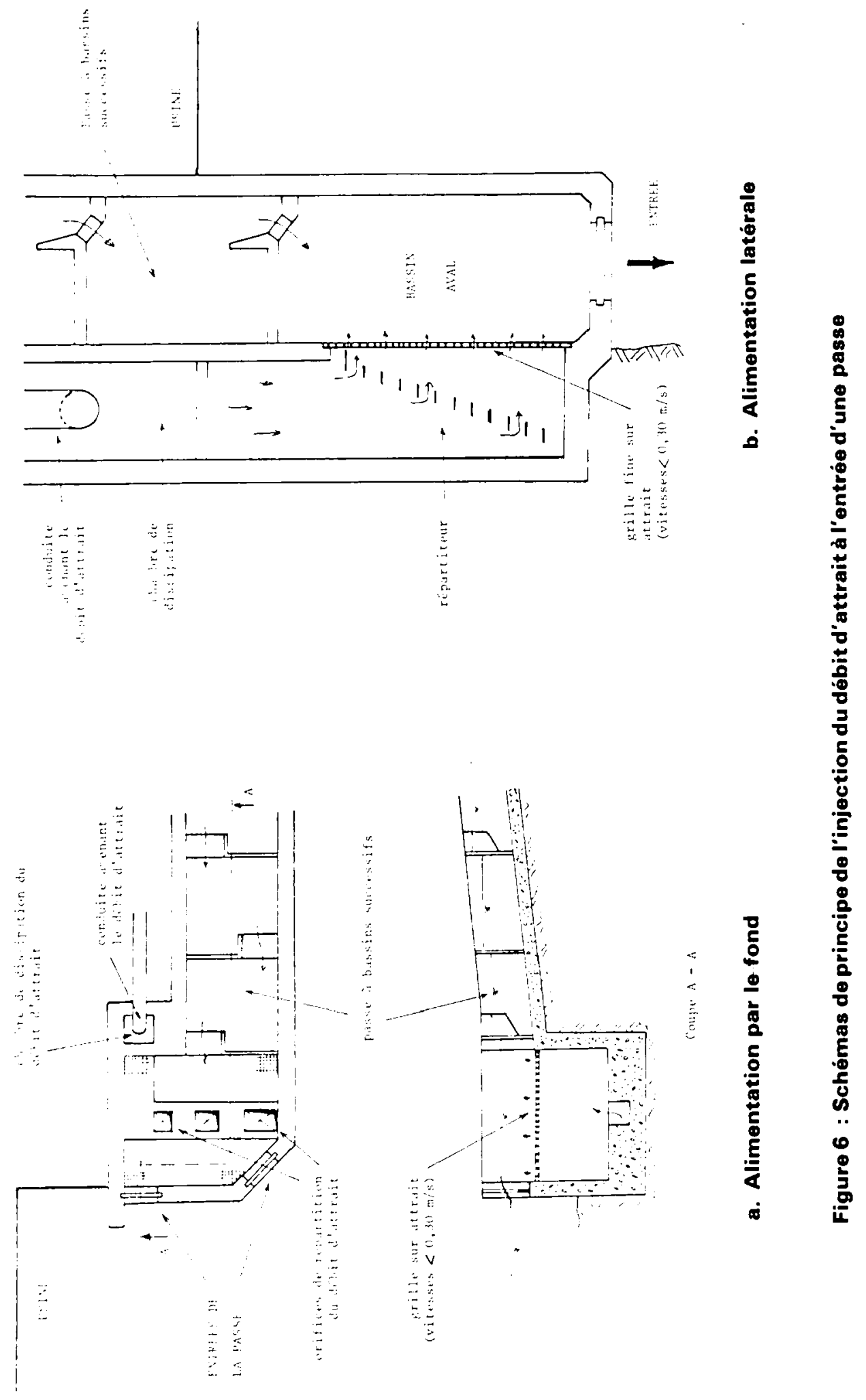


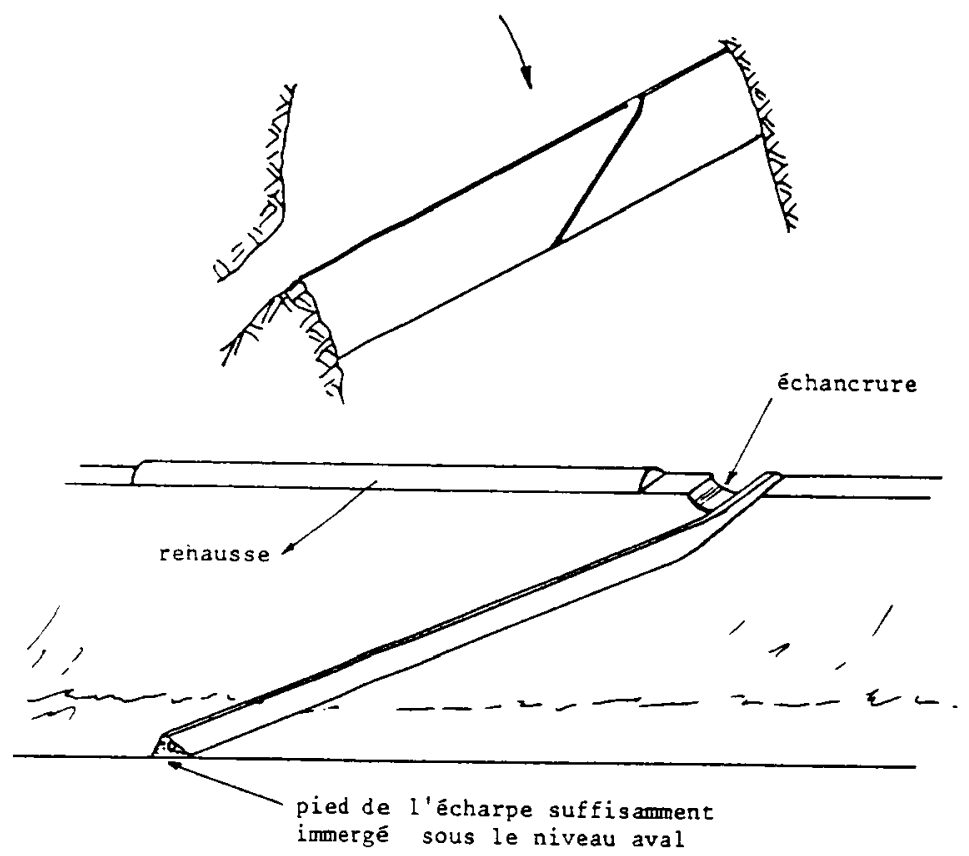

Figure 7 : Passe en écharpe
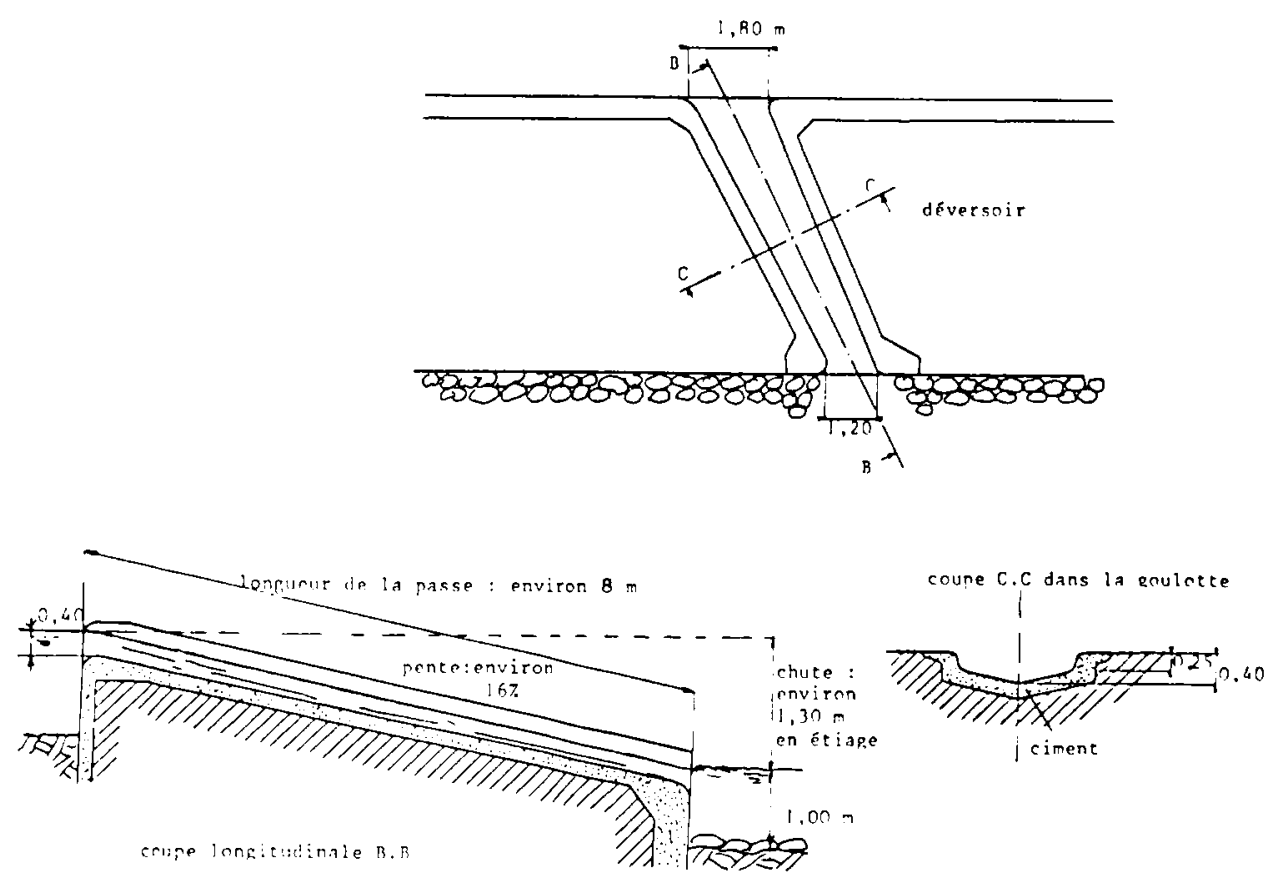

Figure 8 : Passe en entonnoir sur l'Elle (Barrage de Kergiorc'h) 


\section{LES PASSES A BASSINS SUCCESSIFS}

\subsection{Types}

- Parois déversantes (déversement tout au long de la cloison séparant deux bassins) ou échancrures

- Orifices noyés

- Mixte (parois déversantes ou échancrures - orifices)

- Fentes verticales (une ou deux fentes)

\subsection{Dénivellation entre deux bassins (DH)}

2.2. 1. Passes à parois ou échancrures déversantes à jets plongeants : (le poisson doit sauter dans la lame d'eau pour passer d'un bassin à l'autre)

Saumons et truites de mer : de 0,30 à $0,60 \mathrm{~m}$; de préférence : $0,30-0,40 \mathrm{~m}$

Truites de 0,30 à $0,45 \mathrm{~m}$; de préférence : $0,30 \mathrm{~m}$

Aloses et Poissons blancs : à éviter.

2.2.2. Passes à parois déversantes, à échancrures et passe mixte à jet de surface : (le poisson peut passer d'un bassin à l'autre en nageant dans la lame d'eau) Saumons et truites de mer: de 0,30 à $0,45 \mathrm{~m}$; de préférence $0,30-0,40 \mathrm{~m}$ Truites environ $0,30 \mathrm{~m}$

Aloses

Poissons blancs de 0,20 à $0,30 \mathrm{~m}$; de préférence : $0,20-0,25 \mathrm{~m}$

(suivant les espèces)

2.2.3. Passes à orifices noyés

Identiques à 2.2.2. ; à éviter pour l'alose.

2.2.4. Passes à fentes verticales

Saumons, truites de mer, truites:

Aloses:

$$
0,30 \mathrm{~m}
$$

de 0,20 à $0,30 \mathrm{~m}$; de préférence : $0,20-0,25 \mathrm{~m}$

\section{Remarques :}

On a rarement intérêt à trop augmenter des chutes entre deux bassins (sauf peutêtre à l'entrée de la passe pour rendre celle-ci plus attractive); on verra, en effet, que le volume utile des bassins doit être proportionnel à cette chute.

Dans le cas des passes à fentes verticales, ce ne sont pas les vitesses de nage des migrateurs qui limitent la chute entre deux bassins, mais la nécessité de réduire les vitesses dans les fentes de façon que celles-ci, compte tenu du débit, soient suffisamment larges pour permettre le passage des migrateurs.

\subsection{Volume utile (volume d'eau) des bassins (V)}

Basé sur une puissance dissipée maximale par unité de volume d'eau dans les bassins (P/V) comprise entre 150 et 200 watts $/ \mathrm{m}^{3}$.

$\mathrm{P} / \mathrm{V}=\frac{9810 \times \mathrm{Q} \times \mathrm{DH}}{\mathrm{L} \times \mathrm{B} \times \mathrm{Tmoy}}$

$\mathrm{P} / \mathrm{V}$ : puissance dissipée par unité de volume (watts $/ \mathrm{m}^{3}$ )

$\mathrm{O}$ : débit dans la passe $\left(\mathrm{m}^{3} / \mathrm{s}\right)$

$\mathrm{DH}$ : chute entre deux bassins $(\mathrm{m})$

$L \quad$ : longueur des bassins $(m)$

B : largeur des bassins (m)

Tmoy: profondeur d'eau moyenne dans le bassin pour le débit considéré $(\mathrm{m})$

Grosses passes à salmonidés : prendre 200 watts $/ \mathrm{m}^{3}$

Petites passes, passes à aloses: prendre 150 watts $/ \mathrm{m}^{3}$

Si la passe ne comporte que quelques bassins, des valeurs sensiblement plus importantes de $P / V$ peuvent être prises pour les salmonidés. 


\subsection{Dimensions des bassins (L, B)}

La forme optimale des bassins - leur volume utile étant fixé - est liée à la configuration et à l'orientation des jets, c'est-à-dire au mode de communication entre bassins (formes et dimensions des fentes, orifices ou échancrures, niveaux d'eau de part et d'autre de la cloison). Il convient d'éviter les phénomènes de "court-circuit ", c'est-àdire le passage direct d'un jet à forte vitesse d'un bassin au suivant sans dissipation d'une fraction suffisante de son énergie cinétique. A l'opposé, les jets ne doivent pas heurter trop violemment les parois car cela peut perturber le comportement du migrateur.

De façon générale, il est préférable de ne pas trop s'écarter des caractéristiques de passes existantes et ayant démontré leur efficacité. Pour ces passes, la longueur $L$ est généralement comprise entre 7 et $12 \mathrm{~d}$, d étant :

- Passe à échancrures : valeur la plus petite de la largeur de l'échancrure ou de la charge sur l'échancrure

- Passe à parois déversantes: charge sur la paroi

- Passe à fentes verticales: largeur de la fente

- Passe à orifices noyés : diamètre ou plus petite dimension de l'orifice.

\subsection{Dimensions minimales des échancrures, des orifices et des fentes}

1. Echancrures * et fentes

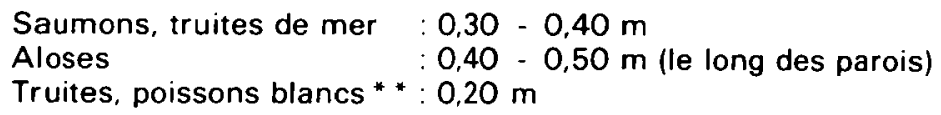

\section{Orifices}

Saumons, truites de mer :0,10 à $0,15 \mathrm{~m}^{2}$ Truites, poissons blancs **: 0,05 à $0,10 \mathrm{~m}^{2}$

\subsection{Estimation des débits et calage des passes à bassins}

Les formules usuelles d'hydraulique donnant les débits au-dessus des déversoirs (épais ou en mince paroi, avec ou sans contraction, noyés ou dénoyés suivant le cas )et à travers les orifices permettent de déterminer de façon approchée le débit dans une passe en fonction des caractéristiques des cloisons (dimensions des échancrures, fentes et orifices), du calage de la passe (cotes de déversement des échancrures ou des fentes. dénivellation entre deux cloisons successives) et des niveaux d'eau amont et aval.

II est nécessaire d'étudier le comportement hydraulique de la passe (évolution du débit, de la puissance dissipée par unité de volume, des chutes entre bassins) pour les différentes conditions de niveaux amont et aval en période de migration.

Si, à partir d'un certain niveau à l'amont, les conditions hydrauliques deviennent incompatibles avec le passage du poisson, il convient de prévoir un dispositif de régulation en amont ou de se tourner vers un autre type de passe.

Lors du contrôle du débit en amont d'une passe, il faut veiller à ne pas créer localement une singularité (chute, mise en vitesse) susceptible de bloquer le migrateur. C'est pourquoi ce contrôle ne peut généralement s'effectuer qu'en intervenant sur plusieurs bassins dans la partie amont de la passe (succession de déversoirs réglables, section amont à fentes verticales ou à orifices noyés).

* Lorsque le poisson doit passer d'un bassin à l'autre en sautant, adopter des valeurs sensiblement plus grandes $(0,50 \mathrm{~m}$ pour les saumons et truites de mer et $0,30 \mathrm{~m}$ pour les truites)

* Si ces dimensions devraient convenir à la majorité des espèces de poissons blancs, il est possible qu'elles se révèlent insuffisantes pour certaines espèces particulières, comme le brochet, dont on connaît peu le comportement dans les passes. 

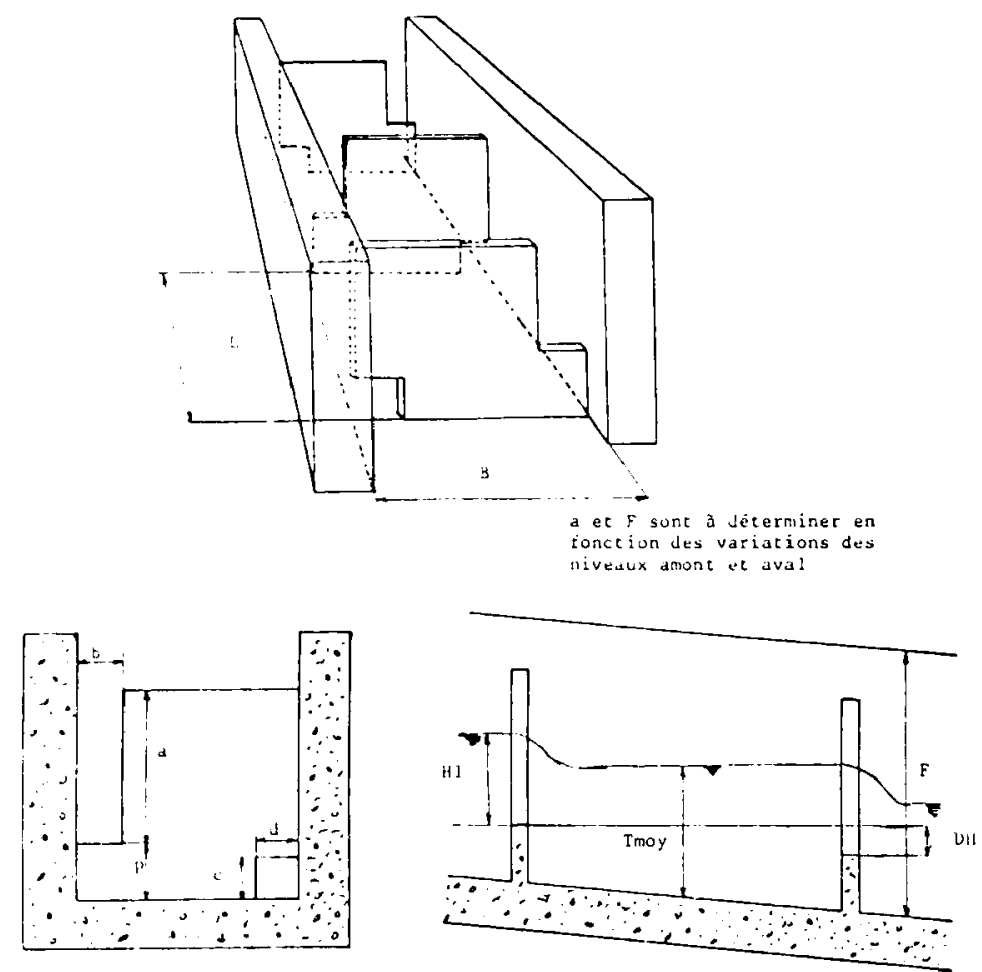

\begin{tabular}{|c|l|c|c|c|}
\hline$n$ & Débit (m $\left.{ }^{3} / \mathrm{s}\right)$ & 0,125 & 0,250 & 0,500 \\
\hline $\mathrm{L}$ & Longueur (m) & $2,0 \mathrm{C}$ & 2,50 & 3,00 \\
\hline $\mathrm{B}$ & Largeur (m) & 1,25 & 1,50 & 1,80 \\
\hline Tmoy & Profondeur moyenne (m) & 1,00 & 1,30 & 1,55 \\
\hline $\mathrm{b}$ & Largeur êchancrure (m) & 0,20 & 0,30 & 0,40 \\
\hline $\mathrm{p}$ & Pelle (m) & 0,73 & 0,90 & 0,95 \\
\hline Hl & Charge sur échancrure (m) & 0,42 & 0,55 & 0,75 \\
\hline $\mathrm{cxd}$ & Dimensions orifice (m) & $0,15 \times 0,15$ & $0,2 \times 0,2$ & $0,3 \times 0,3$ \\
\hline DH & Denivellation entre 2 bassins (m) & 0,30 & 0,30 & 0,30 \\
\hline
\end{tabular}

Figure 9 : Passe à bassins à échancrures latérales et orifices noyés (d'après LARINIER ot MIRALLES) 


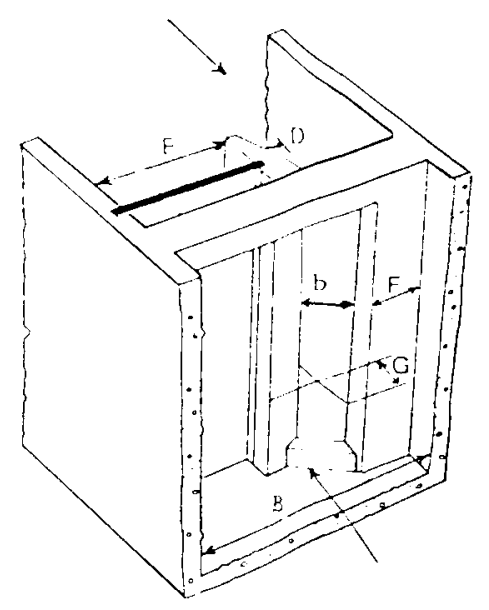

\begin{tabular}{|c|c|c|c|c|}
\hline$:$ & largeur du bassin & 1.80 & 2,40 & 3.00 \\
\hline 1. & longueur du bessin & 2.75 a 3.00 & 3.00 & 5.00 \\
\hline$b$ & Larceur de la lente & 0.30 & 0.30 & 0.60 \\
\hline (1) & Arojle du deflecteur central & 0.18 & 0.18 à 0.20 & 0.40 \\
\hline F & Distance du deflecteur a la paroi & 0.94 & 1.25 a 1.52 & 1,10 \\
\hline $\mathrm{F}$ & Longlentur du deflecteur de paroi & 0.40 & 0.40 a 0.63 & 0.84 \\
\hline $\mathrm{C}$ & Decalage des deflecteurs & 0.14 & 0,14 & 0.30 \\
\hline
\end{tabular}

vita: les cotes sont donnces en mètres

Figure 10 : Caractéristiques des passes à fentes verticales (d'après BELL) 


\section{3. ÉCLUSES ET ASCENSEURS}

3.1. Une écluse (Fig. 11) se compose d'une chambre amont située au niveau de la retenue reliée à une chambre aval de grandes dimensions par un conduit incliné ou un puits vertical. A chaque extrémité des chambres sont installées des vannes, la plupart du temps automatisées.

\subsection{Le cycle de fonctionnement peut se résumer ainsi}

- Phase d'attrait : le migrateur est attiré dans la chambre aval, le débit dans l'écluse étant contrôlé par la vanne amont.

- Phases de remplissage et de sortie: la vanne aval est fermée, le poisson suit la surface libre lors du remplissage de l'écluse. On incite le poisson à passer dans la retenue en établissant un courant d'attrait par l'ouverture d'un by-pass dans la chambre inférieure.

- Phase de vidange : au bout d'un certain temps, on procède à la réouverture de la vanne aval et à la vidange de l'écluse. Cette vidange doit être suffisamment lente pour éviter de trop fortes mises en vitesse à l'entrée de l'écluse.

3.3. L'efficacité d'un tel dispositif est liée non seulement à son attractivité ( ${ }^{*}$ ), mais aussi au comportement du poisson dans l'écluse qui doit demeurer dans la chambre aval pendant toute la phase d'attrait, suivre le niveau de l'eau lors de la phase de remontée et sortir de l'écluse avant la vidange. A cet égard, il est nécessaire que les vitesses et les turbulences dans la chambre aval restent acceptables. Il faut d'autre part éviter un remplissage trop rapide entraînant des turbulences exagérées et un fort entraînement d'air à la surface qui peuvent inciter le poisson à rester dans la chambre inférieure.

Il est impossible de déterminer a priori quelles seront les conditions hydrauliques optimales pour les migrateurs. C'est pourquoi il convient de donner au fonctionnement de l'écluse un maximum de flexibilité (dans la durée de chaque phase du cycle, dans le degré et le temps d'ouverture des vannes amont et aval, etc.).

3.4. Malgré ces précautions, de nombreuses écluses se sont révélées peu ou pas efficaces. Ces difficultés, tenant au comportement de certaines espèces, ont été tournées aux États-Unis et en U.R.S.S. de la façon suivante (Fig. 12):

- Les migrateurs sont piégés dans un vaste bassin de stabulation situé au pied de l'écluse.

- Ils sont ensuite poussés dans le sas à l'aide d'une grille mobile fixée sur un chariot se déplaçant sur des rails horizontaux le long des parois latérales du bassin.

- Un carrelet mobile suivant le niveau de l'eau lors de la période de remplissage oblige les poissons à passer à l'amont.

3.5. Le principe de l'ascenseur est très voisin du système précédent : il consiste à piéger les migrateurs dans une cuve au pied de l'obstacle, puis à élever et déverser celleci à l'amont.

(*) Comme pour tout dispositif de franchissement, l'écluse doit être bien située. Son débit étant généralement limité à quelques centaines de litres/seconde, il peut s'avérer nécessaire de prévoir un débit auxiliaire d'attrait. La vanne aval doit ètre asservie au niveau d'eau aval pour conserver des vitesses suffisantes à l'entrée lorsque ce niveau varie. Il est enfin préférable d'éclairer la chambre inférieure de façon à assurer une transition au point de vue éclairement entre le milieu extérieur et l'écluse. 
Pour garantir une efficacité suffisante du dispositif, comme dans le cas de l'écluse il est préférable

- soit d'empêcher les migrateurs de sortir de la cuve une fois qu'ils y ont pénétré (système de $\mathrm{V}$ ou grille anti-retour)

- soit d'attirer et de piéger les migrateurs dans un vaste bassin de stabulation puis de les obliger à passer au-dessus de ta cuve en les poussant à l'aide d'une grille mobile (Fig. 13).

3.6. Que ce soit pour un ascenseur ou une écluse, la conception de la prise d'eau pour le débit d'attrait peut s'avérer délicate en cas de fort marnage de la retenue amont et surtout de stratification thermique ou chimique de cette dernière.
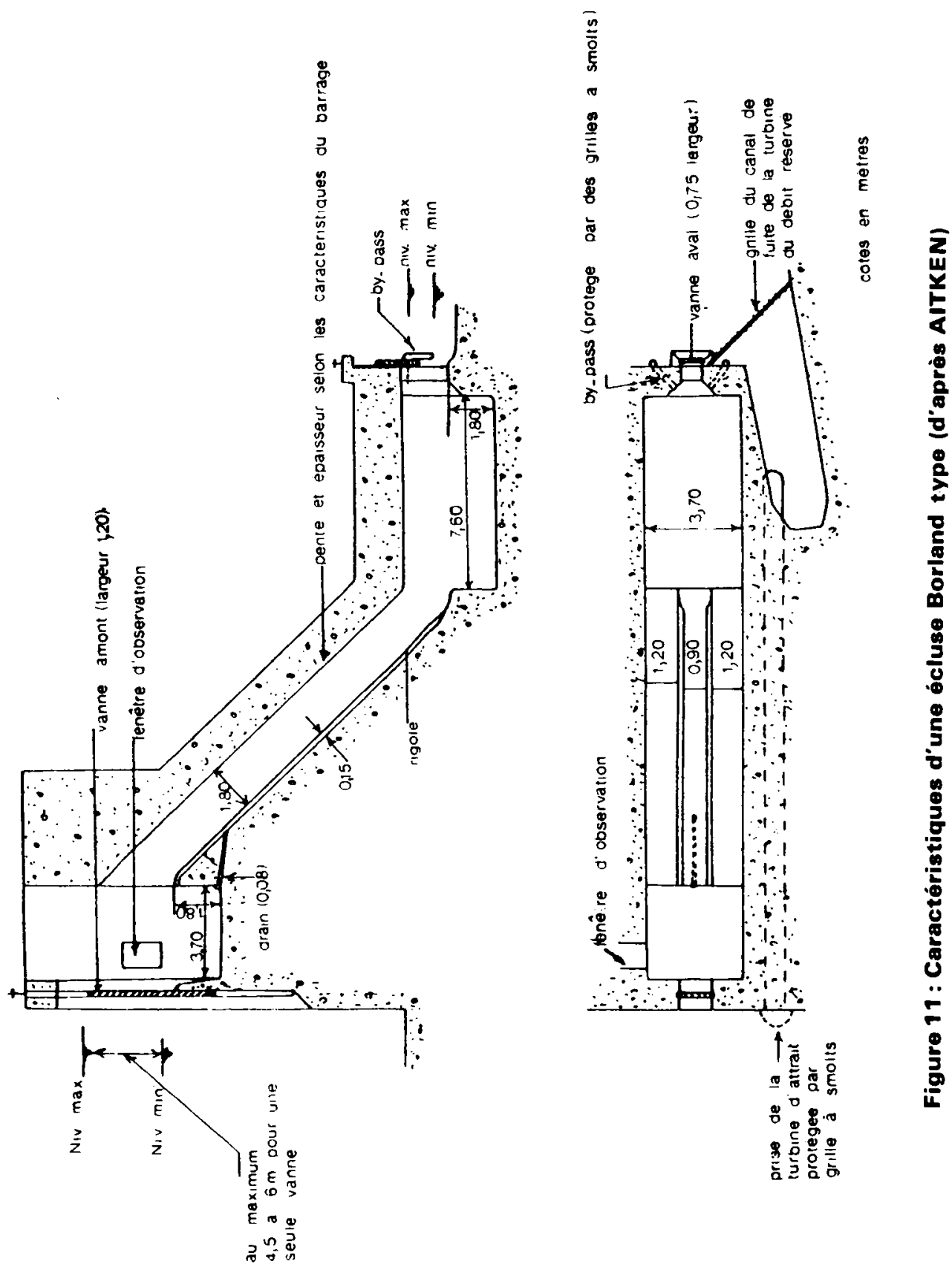


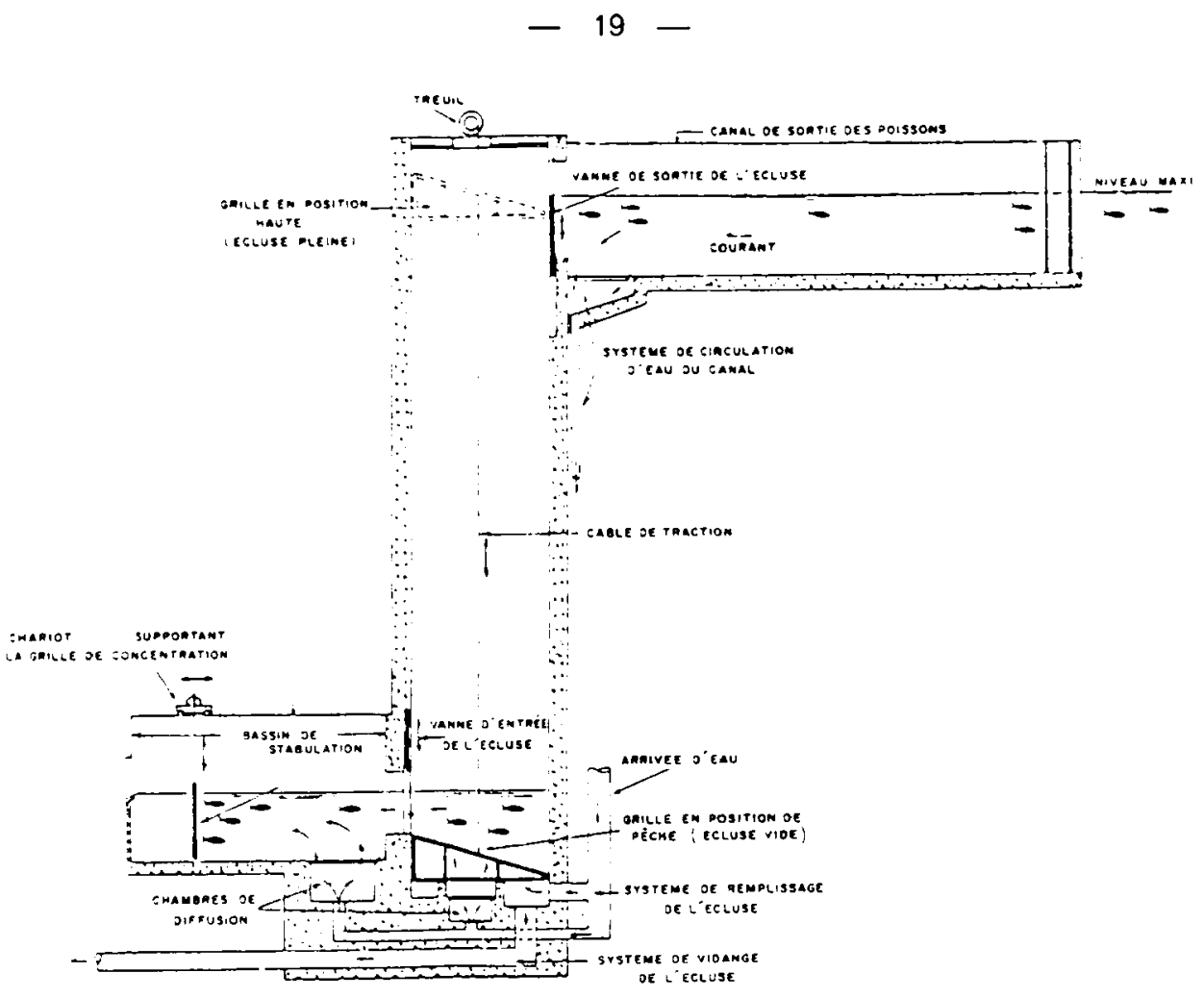

Figure 12: Schéma de principe d'une écluse à poissons munie d'un système obligeant les migrateurs à passer à l'amont (d'après RIZZO)

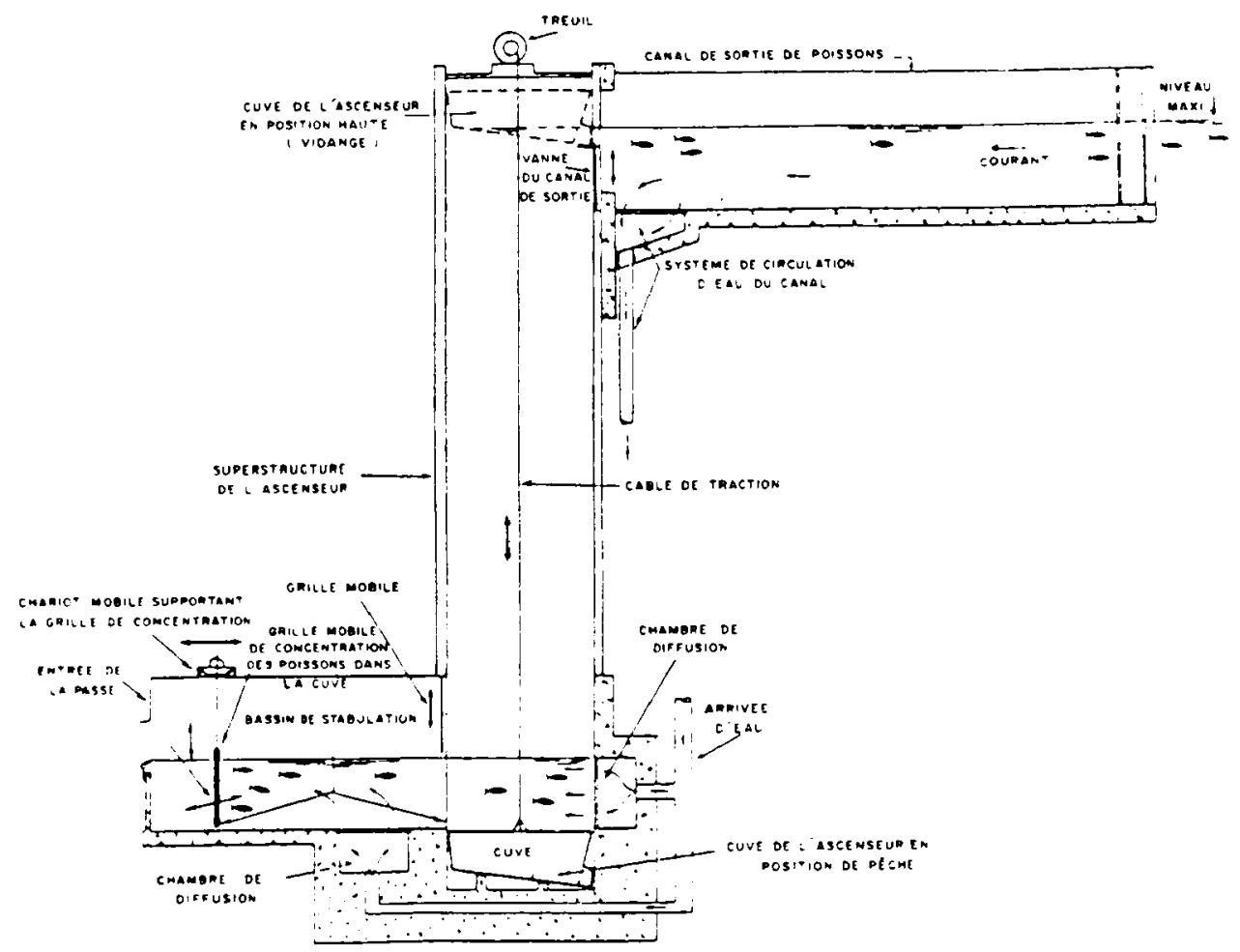

Figure 13 : Schéma de principe d'un ascenseur à poissons - Côte Est des États Unis (d'après RIZZO) 


\section{LES PASSES A RALENTISSEURS}

4.1. La conception et l'installation d'une passe à ralentisseurs est plus délicate que celle d'une passe à bassins successifs

4.2. II existe un grand nombre de types de ralentisseurs. Certains sont encore expérimentaux car ils ont été peu utilisés et l'on connaît donc mal l'étendue de leur domaine de fonctionnement. Sont données dans la suite, à titre d'exemple, les caractéristiques de ralentisseurs déjà testés in situ et ayant démontré leur efficacité.

4.3. Les caractéristiques géométriques des ralentisseurs sont données sous forme adimensionnelle. Toutes les dimensions sont rapportées à une longueur caractéristique (largeur du canal ou hauteur des ralentisseurs). Il est impératif de ne pas s'écarter des caractéristiques géométriques données: tous les ralentisseurs ont été systématiquement testés sur modèle réduit et toute modification peut se traduire par une altération notable de la structure de l'écoulement préjudiciable à l'efficacité du dispositif.

4.4. Le poisson franchit une passe à ralentisseurs d'une seule traite. II ne peut se reposer entre les ralentisseurs. C'est pourquoi, lorsque la dénivellation devient importante, le migrateur doit fournir un effort intense, et il semble préférable de prévoir des bassins de repos (de façon générale tous les deux mètres de chute environ).

4.5. Les volées des passes à ralentisseurs doivent être rectilignes : tout changement de direction ne peut se faire qu'au niveau d'un bassin de repos d'une longueur suffisante pour que le jet issu de la volée amont ne vienne pas heurter trop violemment les parois (en particulier dans les changements de direction a $180^{\circ}$ ).

4.6. Dans une passe de caractéristiques données, le débit est fixé avant tout par la position du ralentisseur amont par rapport au niveau d'eau amont. Dans une moindre mesure, il peut dépendre des conditions d'entonnement (présence ou non d'arrondis sur les bajoyers, cote du radier à l'amont de la passe)

De façon générale, il convient d'éviter en amont du premier ralentisseur toute contraction ou mise en vitesse susceptible de créer des jets et de retarder "I'amorçage" de la passe (formation des courants en hélice).

4.7. Le radier au niveau de l'entrée de la passe sera suffisamment immergé au. dessous du niveau aval de façon à éviter une accélération locale de l'écoulement préjudiciable au passage du poisson.

4.8. Il est possible de juxtaposer plusieurs bandes de ralentisseurs de fona (Lachadenède, suractifs, chevrons épais, etc.) de façon à obtenir des passes aussi larges que l'on désire, donc susceptibles de transiter un très gros débit.

4.9. Passes à ralentisseurs plans

4.9.1. Caractéristiques géométriques (voir figure 14) 
4.9.2. Conditions d'utilisation :

Saumons, truites de mer: de préférence : $0,8 \mathrm{~m} \leqslant \mathrm{~L} \leqslant 1 \mathrm{~m}$

$$
\begin{array}{ll}
\text { maximum }: L=1,20 \mathrm{~m} & \\
\text { Pentes (valeurs suggérées): } & \\
\text { pour } L=0,80 \mathrm{~m} & I=20 \% \\
\text { pour } L=0,90 \mathrm{~m} & \mathrm{I}=17,50 \% \\
\text { pour } L=1,00 \mathrm{~m} & \mathrm{I}=16 \% \\
\text { pour } L=1,20 \mathrm{~m} & \mathrm{I}=13 \%
\end{array}
$$

Truites:

de préférence : $0,6 \mathrm{~m} \leqslant \mathrm{~L} \leqslant 0,9 \mathrm{~m}$ Pentes (valeurs suggérées)

$$
\begin{array}{ll}
\text { pour } L=0,60 \mathrm{~m} & \mathrm{I}=20 \% \\
\text { pour } L=0,70 \mathrm{~m} & \mathrm{I}=17 \% \\
\text { pour } L=0,80 \mathrm{~m} & \mathrm{I}=15 \% \\
\text { pour } L=0,90 \mathrm{~m} & \mathrm{I}=13,50 \%
\end{array}
$$

4.9.3. Caractéristiques hydrauliques

Les figures 15 et 16 donnent le débit $Q$, le tirant d'eau moyen $h$ en fonction de la pente l et de la charge amont ha (pour des conditions d'entonnement voisines de celles indiquées sur la figure 14).

4.9.4. Valeurs minimales de $h$ (pour permettre la nage du poisson et/ou "l'amorçage" de la passe)

hmin $\sim 0,5$ à $0,6 \mathrm{~L}$

4.10. Passes à ralentisseurs de type FATOU

4.10.1. Caractéristiques géométriques (voir figure 17)

4.10.2. Conditions d'utilisation : identiques à celles de la passe à ralentisseurs plans.

4.10.3. Caractéristiques hydrauliques

Les figures 18 et 19 donnent le débit $Q$ et le tirant d'eau moyen $h$ en fonction de la pente l et de la charge amont ha (pour les conditions d'entonnement voisines de celles indiquées sur la figure 17).

4.10.4. Valeurs minimales de $h$ (pour permettre la nage du poisson et/ou "l'amorçage" de la passe)

hmin $\sim 0,4 \mathrm{~L}$

4.11. Passes à ralentisseurs de fond suractifs de type $A$

4.11.1. Caractéristiques géométriques (voir figure 20)

4.11.2. Conditions d'utilisation:

Saumons, truites de mer : a : valeur conseillée $0,15 \mathrm{~m}$; maximum : $0,20 \mathrm{~m}$

Pentes: pour $a=0,15 \mathrm{~m} \quad I \leqslant 15 \%$

pour $\mathrm{a}=0,20 \mathrm{~m} \quad \mathrm{I} \leqslant 11 \%$

Truites

a : valeur conseillée $0,10 \mathrm{~m}$; maximum : $0,15 \mathrm{~m}$

Pentes: pour $a=0,10 \mathrm{~m} \quad l \leqslant 15 \%$ pour $\mathrm{a}=0,15 \mathrm{~m} \quad 1 \leqslant 10 \%$

4.11.3. Caractéristiques hydrauliques

Les figures 21 et 22 donnent le débit $Q$, le tirant d'eau moyen $h$ en fonction de la pente l et de la charge en amont ha.

4.11.4. Valeurs minimales de $h$ (pour permettre la nage du poisson et/ou "l'amorçage" de la passe)

$\mathrm{hmin} \sim 1.15$ a 

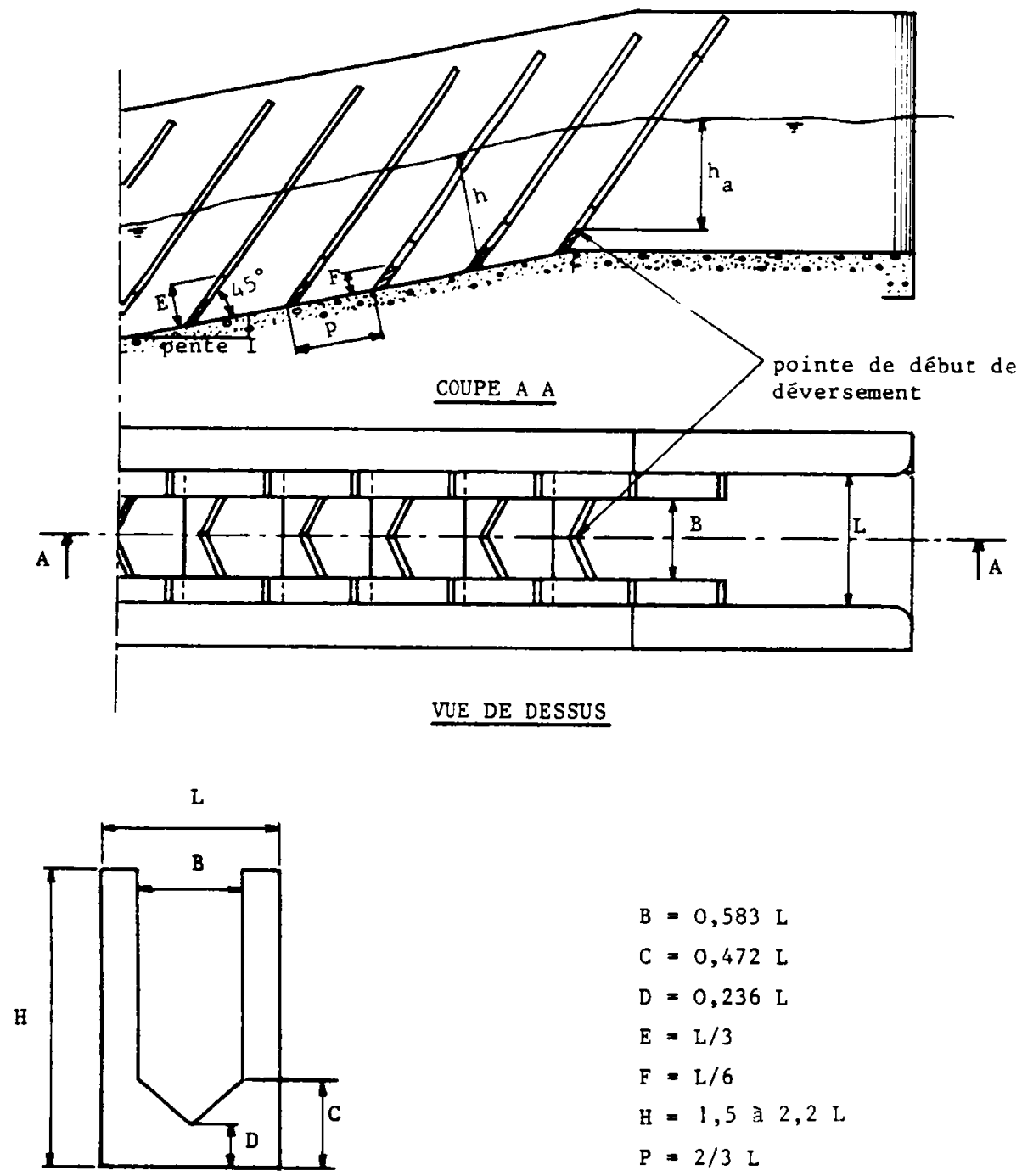

$$
\begin{aligned}
& B=0,583 \mathrm{~L} \\
& C=0,472 \mathrm{~L} \\
& D=0,236 \mathrm{~L} \\
& E=\mathrm{L} / 3 \\
& F=\mathrm{L} / 6 \\
& H=1,5 \mathrm{a} 2,2 \mathrm{~L} \\
& P=2 / 3 \mathrm{~L}
\end{aligned}
$$

Figure 14 : Paramètres caractéristiques de la passe à ralentisseurs plans 

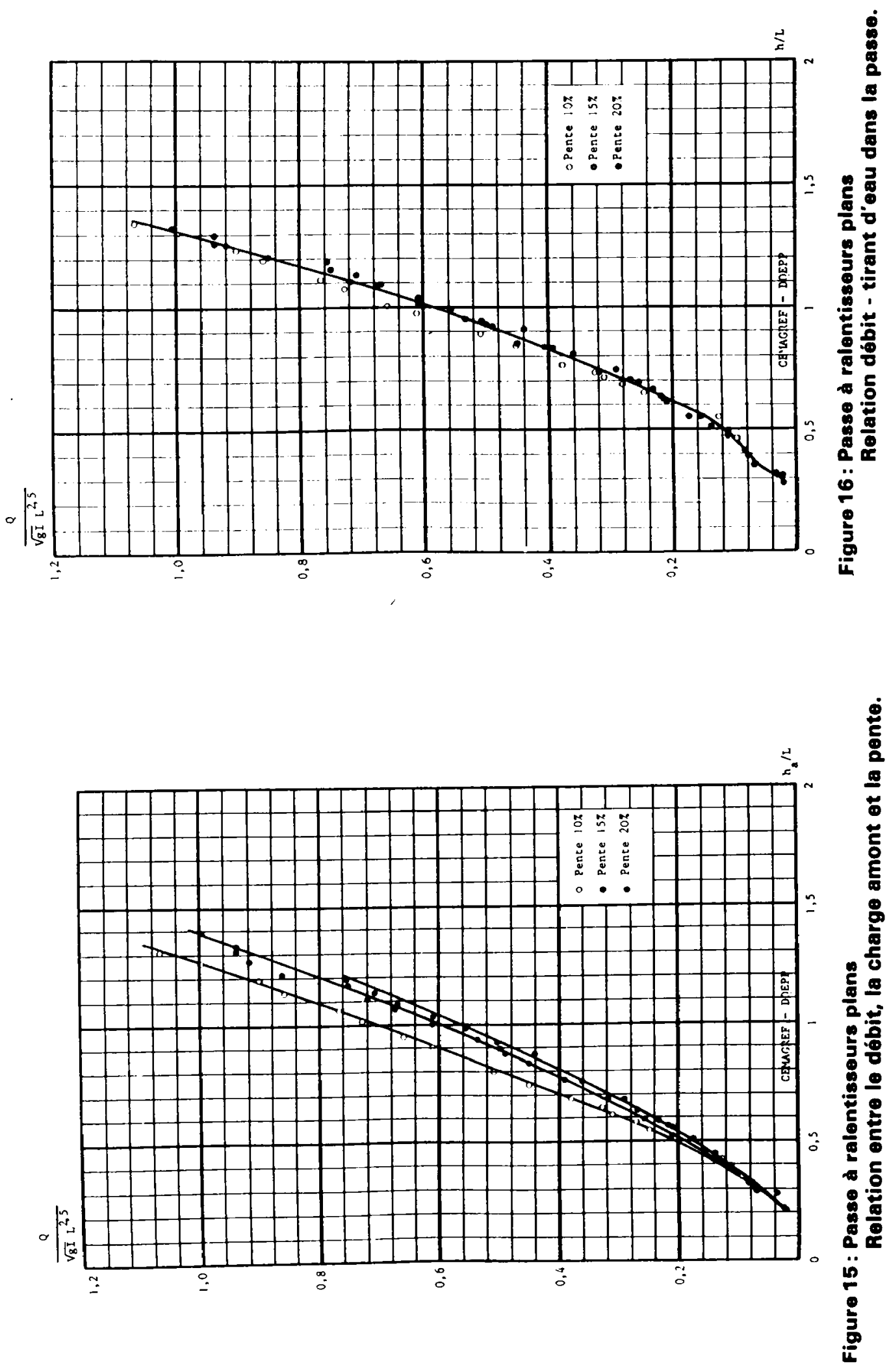

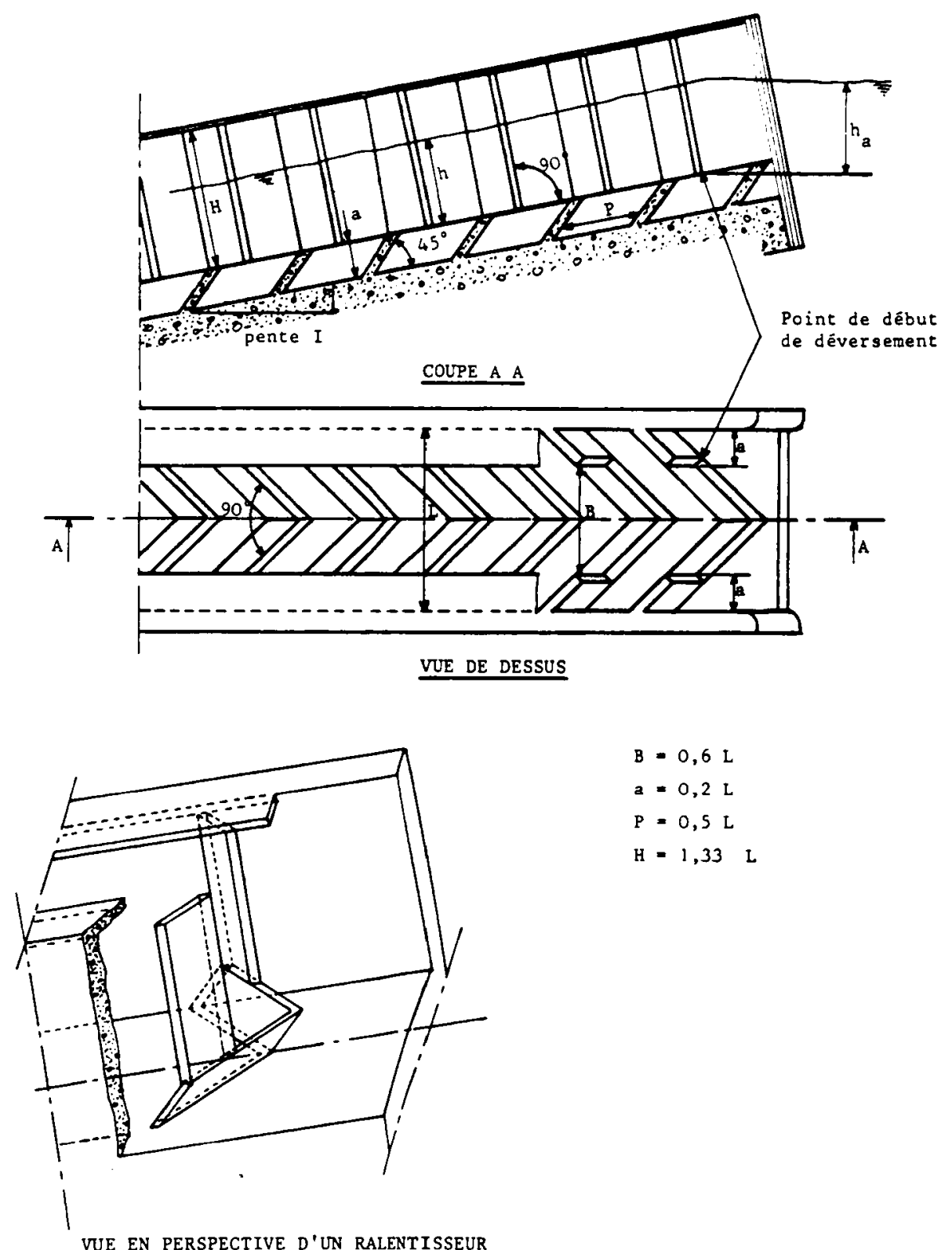

$B=0,6 \mathrm{~L}$

$a=0,2 \mathrm{~L}$

$P=0,5 \mathrm{~L}$

$\mathrm{H}=1,33 \mathrm{~L}$

VUE EN PERSPECTIVE D'UN RALENTISSEUR

Figure 17: Paramètres caractéristiques de la passe à ralentisseurs de type "FATOU" 

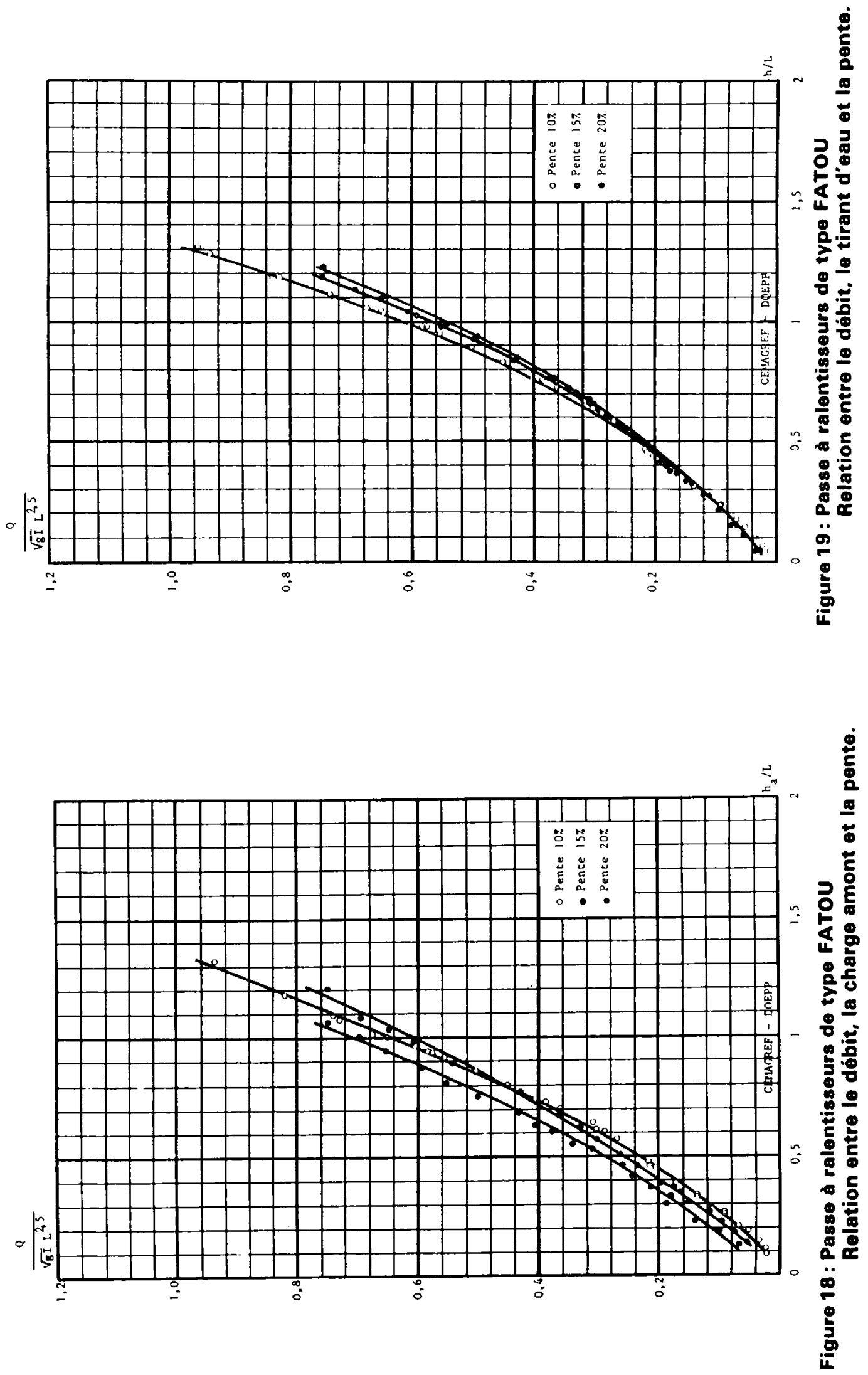


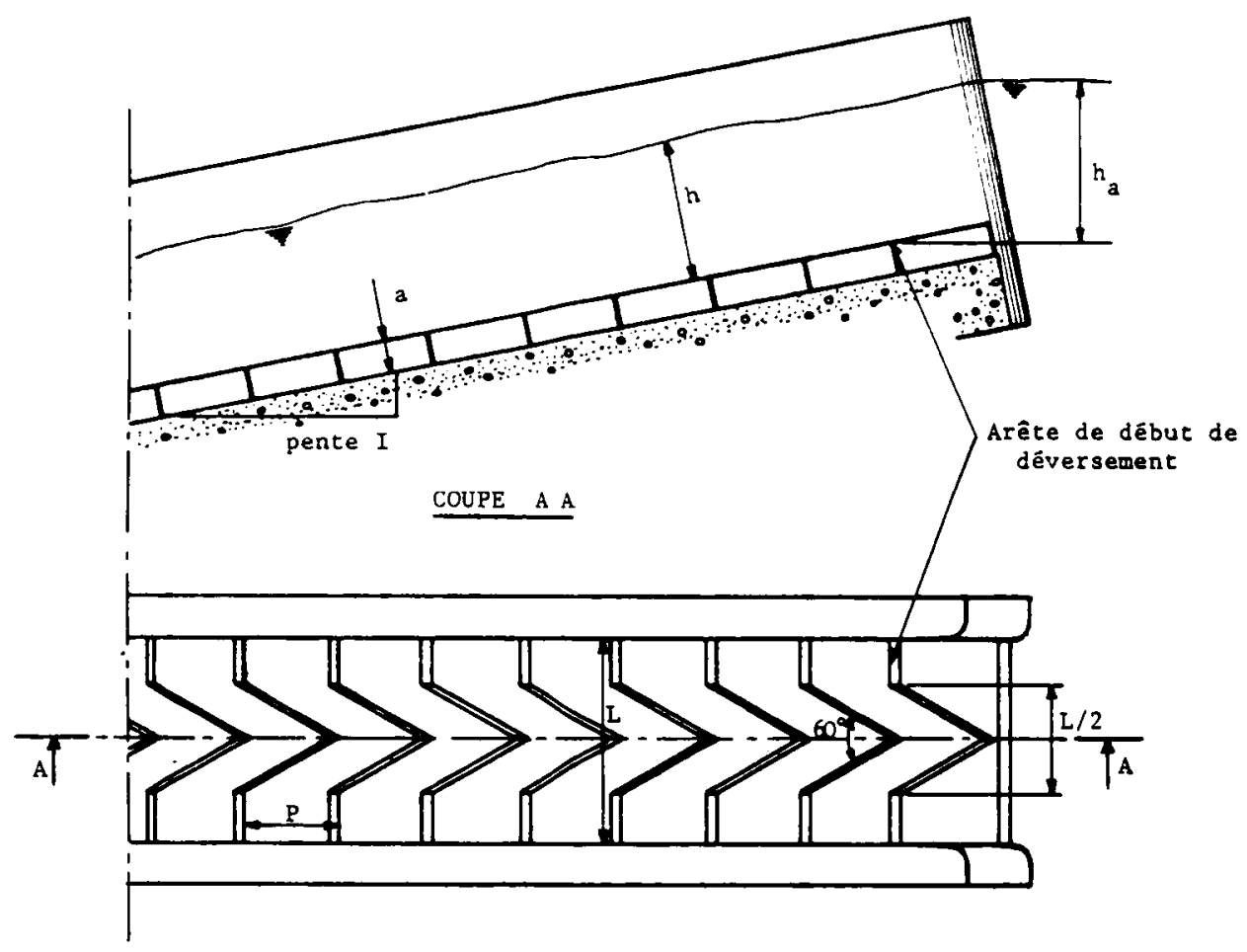

VUE DE DESSUS

$\mathrm{L}=6 \mathrm{a}$

$P=2,60 a$

Figure 20: Paramètres caractéristiques de la passe à ralentisseurs suractifs de fond type $A$ 

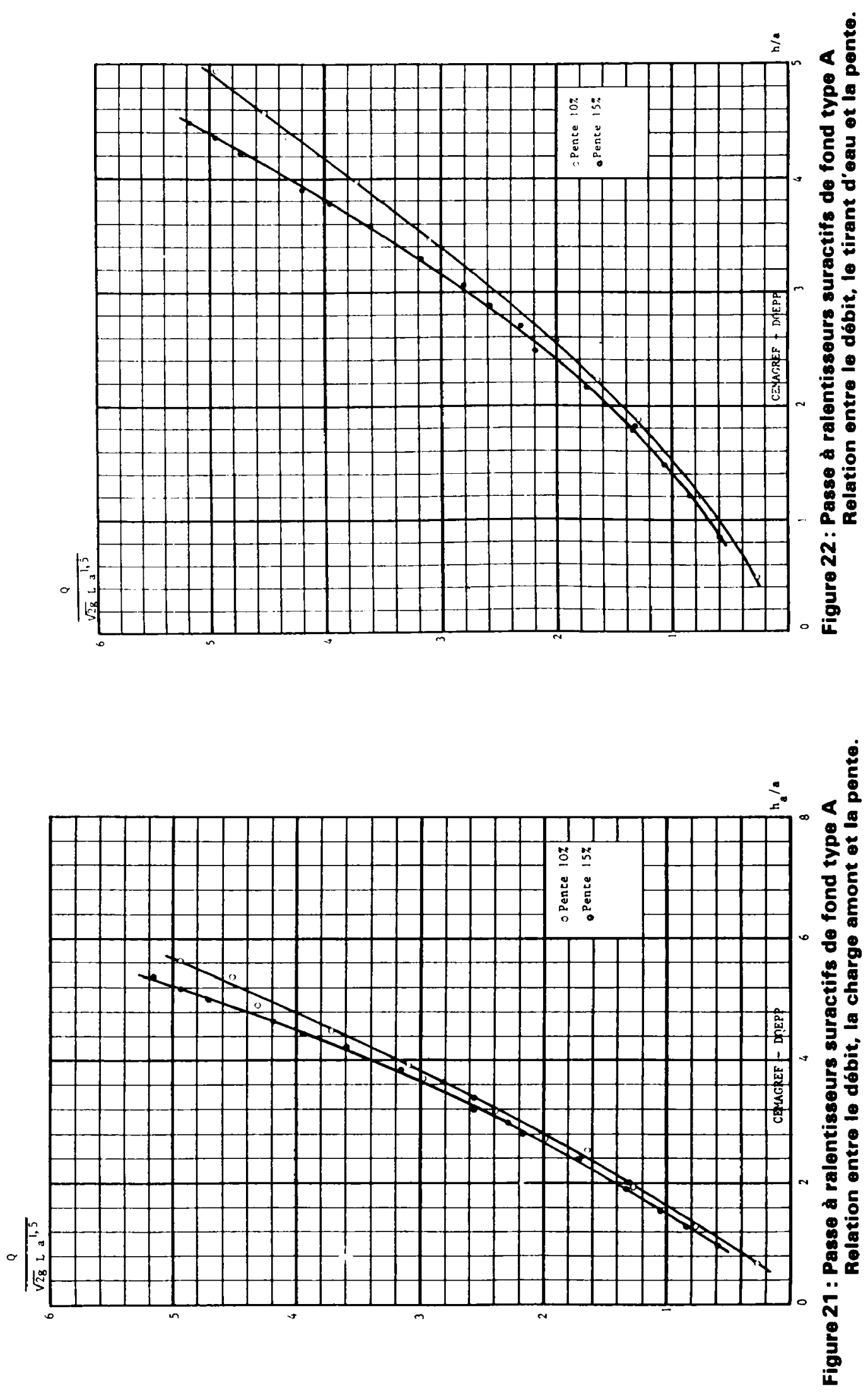


\section{PIÈCEs a incluRe dans Un dossier de PROJET de pASSE A pOISSONS}

La conception d'une passe suppose la connaissance d'un certain nombre de facteurs(d'ordre biologique, topographique, hydrologique et hydraulique) qu' une enquête préliminaire doit permettre de préciser. Ces éléments doivent figurer dans tous les dossiers de passes dans la mesure où leur connaissance est indispensable pour formuler un avis lors d'une consultation.

1. Nom du cours d'eau. Plans de situation (1/20.000 ou $1 / 25.000)$

2. Copie de l'autorisation, du cahier des charges ou des correspondances spécifiant la nécessité de la construction d'une passe à poissons et éventuellement celle d'une glissière à canoë-kayak *

3. Espèces de poissons, périodes de migrations (éventuellement extraits de l'étude ou de la notice d'impact).

4. Caractéristiques hydrologiques du cours d'eau *

- débits moyens mensuels, débits journaliers sur une période suffisante, courbes des débits classés (annuelles et mois par mois).

5. Profil en long de la section du cours d'eau intéressée par l'aménagement. Pente du cours d'eau

6. Plan du site du barrage et topographie sommaire du lit à l'aval de l'ouvrage.

7. Caractéristiques du barrage (ou plus généralement de l'obstacle)

- Nature et rôle du barrage (hydroélectricité, alimentation en eau, tourisme...)

- Configuration du barrage, emplacement et caractéristiques des ouvrages évacuateurs, position de l'usine et des ouvrages annexes. Nombre et caractéristiques des turbines.

- Gestion de l'eau et mode d'exploitation du barrage: importance des débits turbinés, débit réservé, régime de production (fonctionnement au fil de l'eau, par éclusées).

- Niveau amont de retenue normale

- Niveau aval d'étiage.

- Niveaux d'eau amont et aval à considérer en période de migration et débits correspondants.

8. Caractéristiques de la passe et ses annexes.

- Plan de situation

- Plans détaillés comportant profils en long et coupes.

- Note descriptive donnant les caractéristiques de la passe: dimensions des bassins, mode de communication entre bassins (dimensions des échancrures, fentes ou orifices), caractéristiques des ralentisseurs, pente...

- Note précisant le comportement hydraulique de la passe pour les niveaux amont et aval considérés en période de migration (débits, niveaux d'eau...)

- Mode d'injection du débit d'attrait.

- Débits et vitesses à l'entrée de la passe en fonction des débits du cours d'eau.

* Dans certains cas, un dispositif unique peut en effet servir de passe à poissons et de glissière à canoë-kayak. Dans les autres cas, il est de toutes façons préférable de concevoir la glissière et la passe en même temps dans la mesure:

- où se pose le problème de la répartition du débit réservé entre les deux ouvrages

- où le débit transitant dans la glissière peut éventuellement être utilisé comme débit d'attraction pour la passe.

* Ces données sont généralement impossibles à réunir sur la majorité des petits cours d'eau dépourvus de stations de jaugeages. On doit se contenter généralement de renseignements très fragmentaires, qui se révèlent suffisants dans la plupart des cas. Par contre, sur les grands cours d'eau, il est indispensable de définir très clairement la fourchette des débits pour lesquels le dispositif de franchissement doit fonctionner correctement. 


\section{BIBLIOGRAPHIE SOMMAIRE}

AITKEN P.L., DICKERSON L.H., MENZIES W.J.M., 1966. Fish passes and screens at water power works. Proc. Instn. Civ. Engrs. 35, Sept : 29-57

BELL M.C., 1973. Fisheries handbook of engineering requirements and biological criteria. Fisheries Engineering Research Program. U.S. Army Corps of Engineers, North Pacific Division. Portland, Oregon.

CLAY C.H., 1961. Design of fishways and other fish facilities. Ottawa, Department of Fisheries of Canada, $301 \mathrm{p}$.

DALLEY P.J., 1980. A review of fish passage facilities for american shad. Northeast Fish and Wildlife Conference. Ellenville, New York, $32 \mathrm{p}$.

DECKER L.F., 1967. Fishways in Maine. Maine Department of Inland Fisheries and Game. Augusta, Maine, 47p.

JENS G., 1971. Funktion, Bau und Betrieb von Fischpässen. Arch. Fisch. Wiss., 22, Beih. $1,27 \mathrm{p}$.

LARINIER M., 1977. Les passes à poissons. C.T.G.R.E.F. Division Qualité des Eaux, Pêche et Pisciculture, Etude $n^{\circ} 16,126 p$.

LARINIER M., 1978. Étude du fonctionnement d'une passe à poissons à ralentisseurs plans. Bull. fr. Piscic., $271: 40-54$

LARINIER M., TRAVADE F., 1982. Les poissons migrateurs aux États-Unis. Ouvrages de franchissement de barrages. Programmes de restauration des populations. E.D.F. Direction des Études et Recherches. CEMAGREF. Division Qualité des Eaux, Pêche et Pisciculture, $73 \mathrm{p}$.

LARINIER M., MIRALLES A., 1983. Étude expérimentale des passes à ralentisseurs. (en préparation).

LARINIER M., MIRALLES A., 1983. Étude expérimentale des passes à bassins successifs. (en préparation).

RIZZO B., 1969. Fish passage facilities design paramaters for Connecticut river dams. Turners Falls dam. Bureau of Sport Fisheries and Wildlife, Boston, Massachussetts, $33 p$.

TRAVADE F., 1982. Ascenseur à poissons. Critères de conception. Application au barrage de GOLFECH - E.D.F. Direction des Études et Recherches. Département Environnement Aquatique et Atmosphérique. $\mathrm{HE} / 31-82-48,36 \mathrm{p}$.

Photographies 3, 4 et 14: Photo Institut de Mécanique des Fluides Toulouse. 


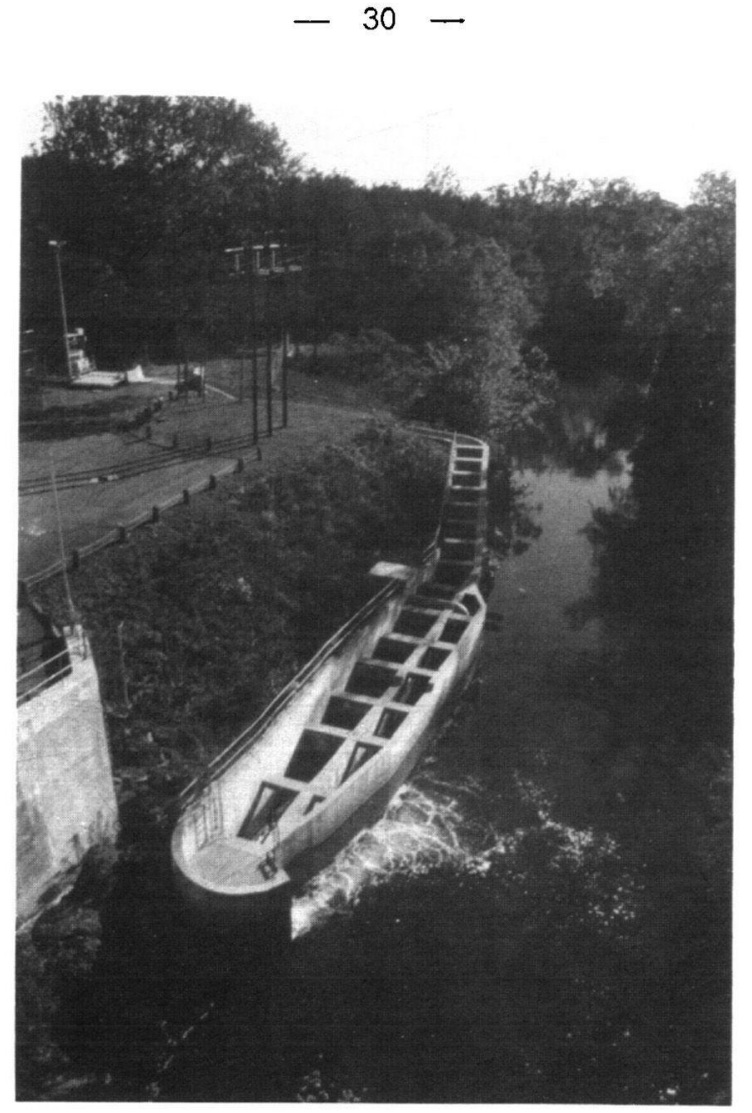

Photo 1 : Entrée de la passe à saumons et aloses au barrage de RAINBOW sur la rivière FARMINGTON (Côte Est des États-Unis). Le débit supplémentaire d'attrait provenant de l'amont (buse visible au centre de la photo) est injecté latéralement dans le premier bassin de la passe après dissipation de son énergie dans une chambre jouxtant la partie aval de la passe.

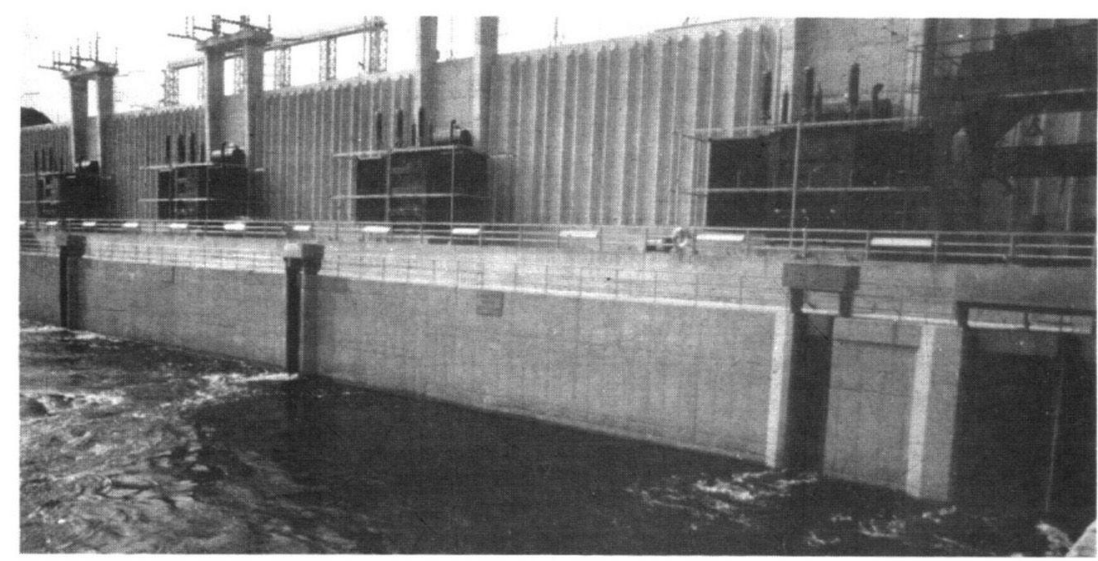

Photo 2 : Canal collecteur situé au-dessus des aspirateurs des turbines au barrage de MACTAQUAC sur la rivière Saint John (Nouveau Brunswick, CANADA). Ce canal collecteur, conduisant les migrateurs vers un dispositif de capture et de transport par camion, comporte 5 entrées : deux entrées principales de $3,6 \mathrm{~m}$ (en rive) et $1,8 \mathrm{~m}$ de largeur, trois entrées secondaires de $0,60 \mathrm{~m}$ de largeur. Des vannes mobiles permettent de conserver des vitesses aux entrées importantes (de 1,30 a $2 \mathrm{~m} / \mathrm{s}$ ) pour des variations du niveau aval de plus de $5 \mathrm{~m}$. 

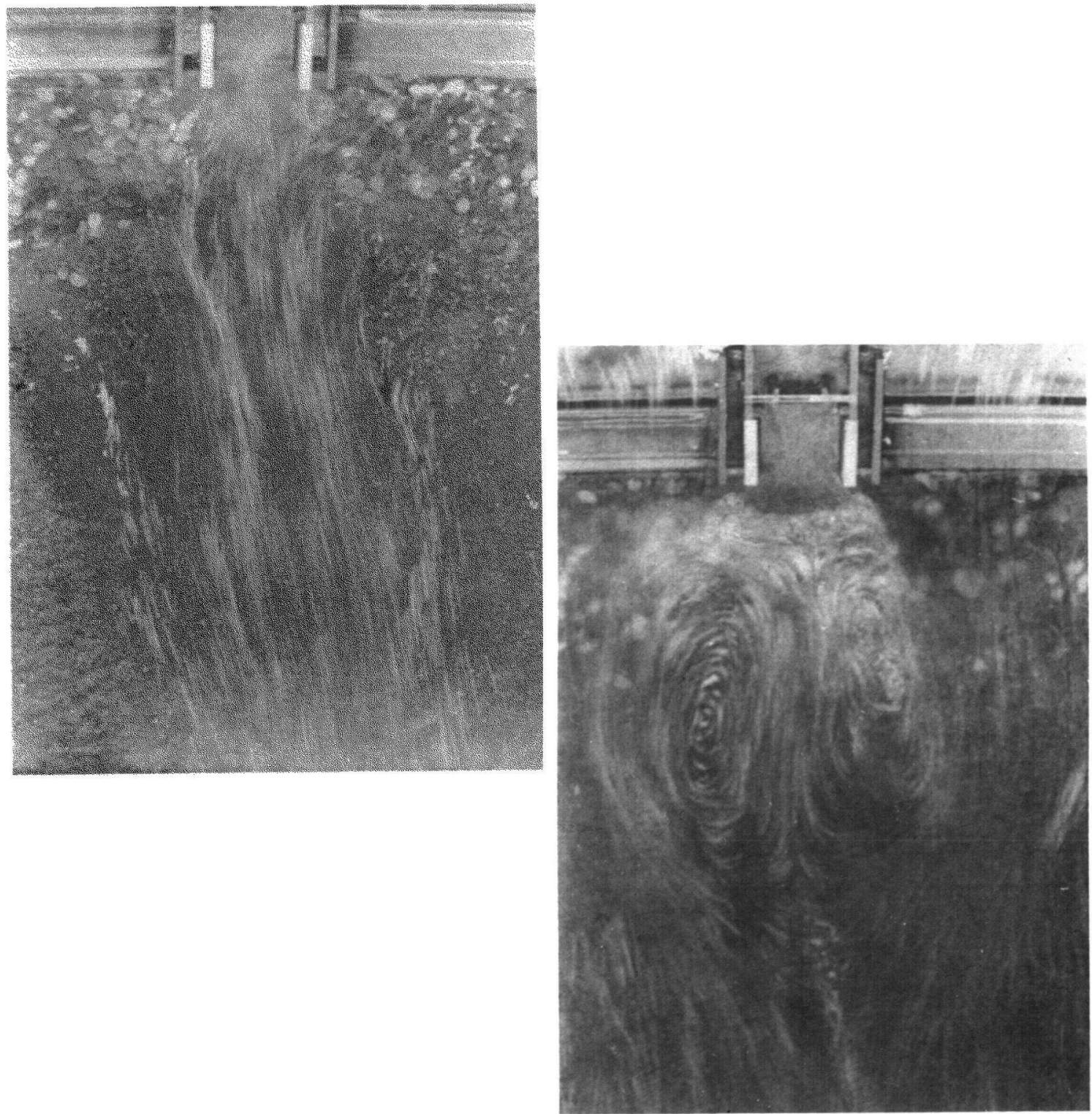

Photo 3 et Photo 4:

Visualisation sur modèle réduit de l'écoulement à l'entrée d'une passe. L'entrée est située en haut et au centre des photographies. Sur la photo 3, le jet issu de la passe se fait sentir relativement loin à l'aval. Par contre, sur la photo 4, l'écoulement transitant par les déversoirs situés de part et d'autre de la passe crée deux zones de recirculation masquant l'entrée de la passe et rendant celle-ci peu attractive. Cette dernière configuration est à éviter dans la mesure du possible. 


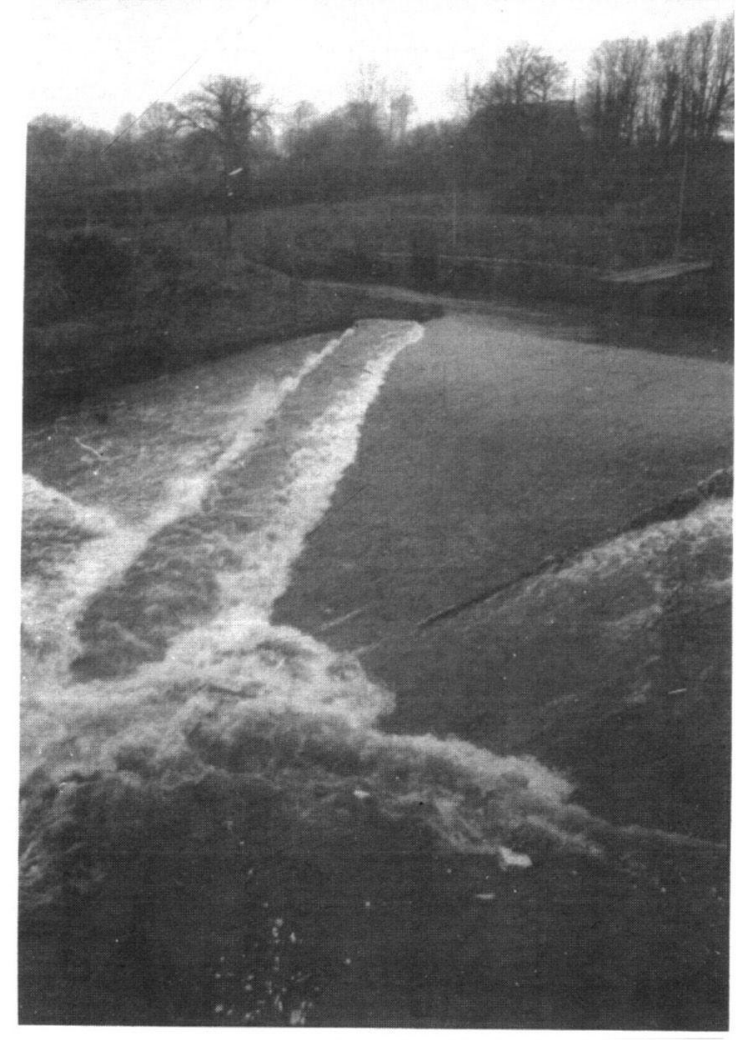

Photo 5 : Passe en écharpe sur la SIENNE à Villedieu (Manche)

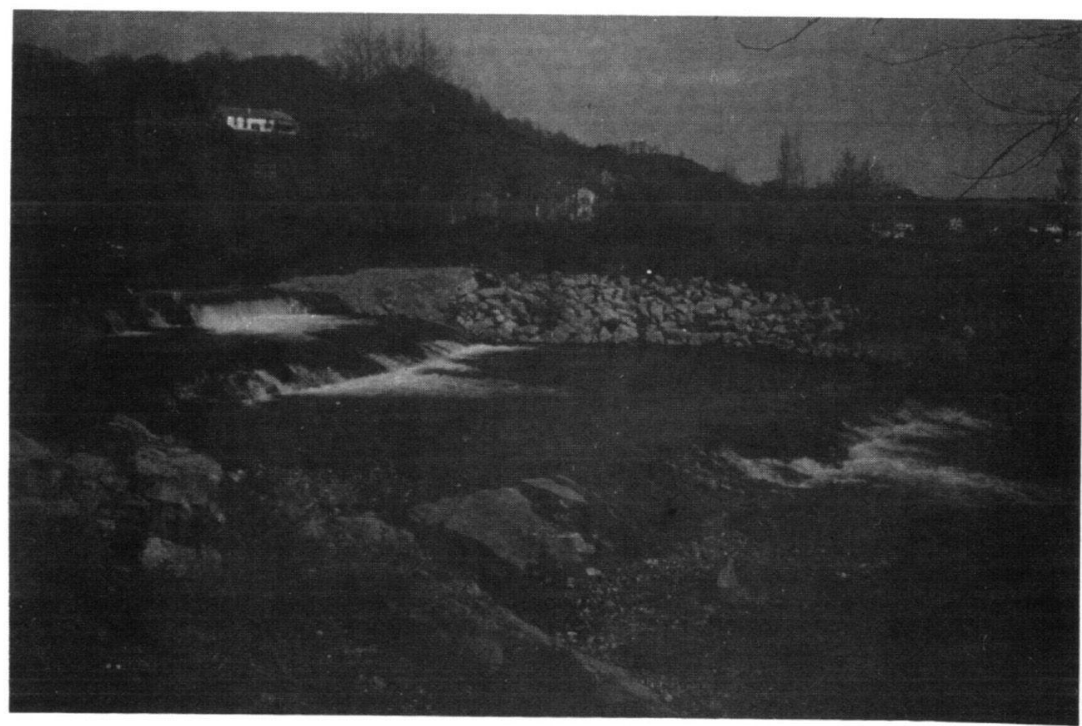

Photo 6 : Seuils en enrochements jointoyés au mastic bitumineux (pente du parement aval : 1/3) permettant le franchissement du barrage de ZALDUBIA sur la NIVELLE (Pyrénées Atlantiques) 


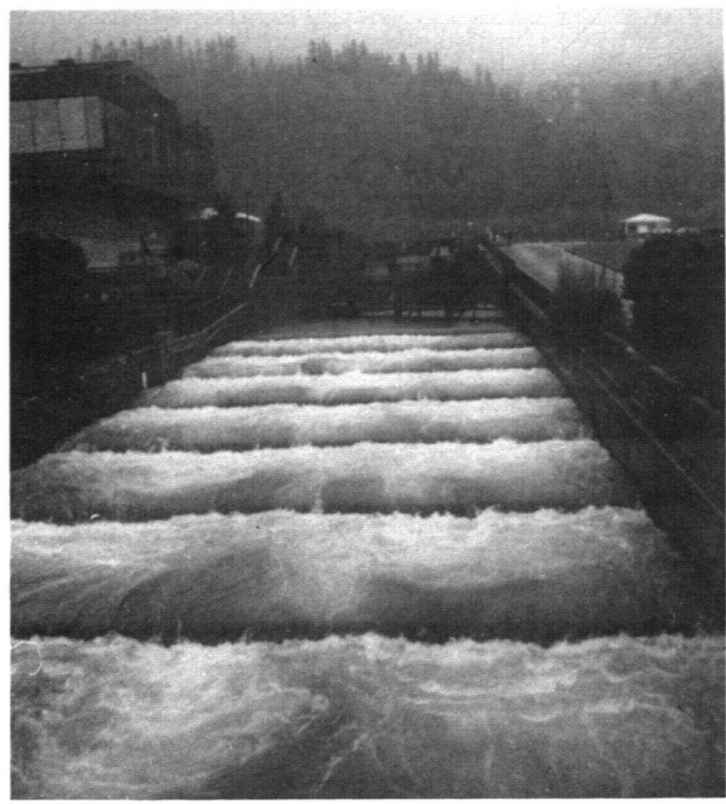

Photo 7 : Passe à bassins successifs à cloisons déversantes au barrage de BONNEVILLE sur la rivière COLUMBIA (Côte Ouest des EtatsUnis). La largeur des bassins varie de 9 à $13 \mathrm{~m}$, pour une longueur de $4,9 \mathrm{~m}$ et un tirant d'eau voisin de $2 \mathrm{~m}$. La dénivellation entre deux bassins successifs est de $0,30 \mathrm{~m}$; la charge sur la cloison, de l'ordre de 0,30 m en temps normal, est portée à 0,40 m environ au printemps pour faciliter le passage des aloses (alosa sapidissima). Cette passe est considérée comme l'une des passes les plus efficaces pour cette espèce.

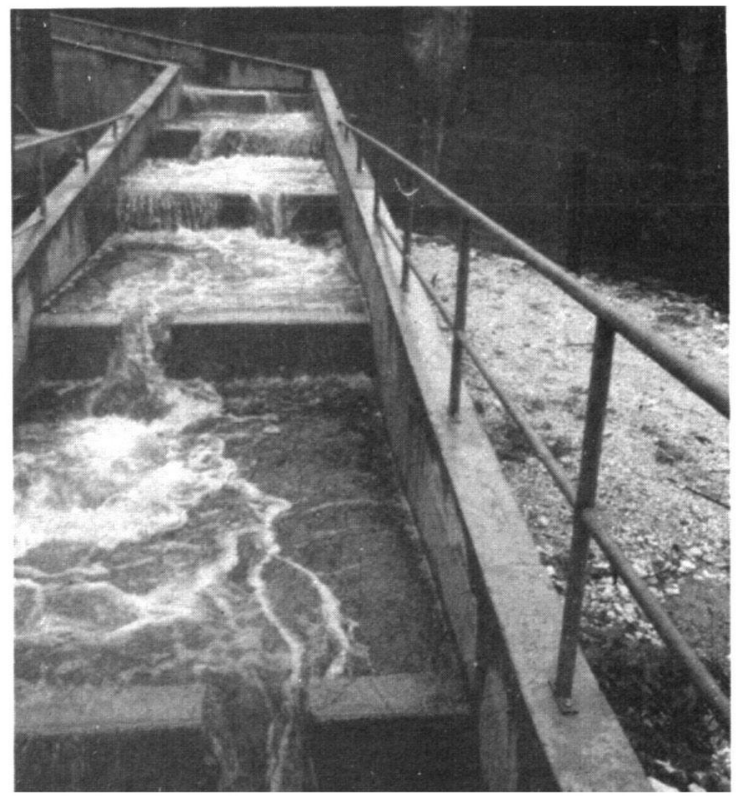

Photo 8 : Passe à bassins successifs à échancrures sur le TY-MAD (affluent du BLAVET - Morbihan) dimensionnée pour un débit voisin de $200 \mathrm{I} / \mathrm{s}$. La longueur et la largeur des bassins sont respectivement de 2,8 et $2 \mathrm{~m}$, le tirant d'eau moyen voisin de $1 \mathrm{~m}$. La dénivellation entre deux bassins est de $0,40 \mathrm{~m}$. 


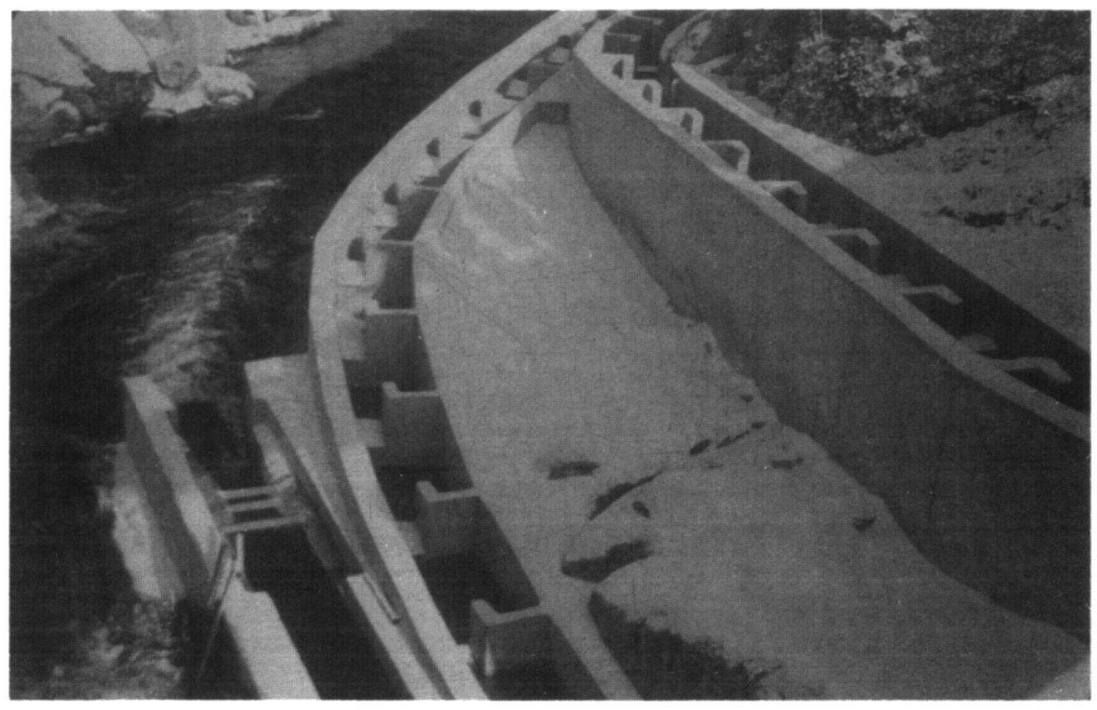

Photo 9 : Passe à bassins successifs mixte à échancrures latérales en plan incliné (largeur : $0,40 \mathrm{~m})$ et à orifices noyés $(0,20 \mathrm{~m} \times 0,20 \mathrm{~m})$ sur le CHAPEAUROUX (barrage de dérivation du CHAPEAUROUX Aménagement de NAUSSAC). La dénivellation entre deux bassins est de $0,15 \mathrm{~m}$, le débit de $150 \mathrm{I} / \mathrm{s}$; longueur : $1,80 \mathrm{~m}$, largeur : $1 \mathrm{~m}$, tirant d'eau : $1,30 \mathrm{~m}$.

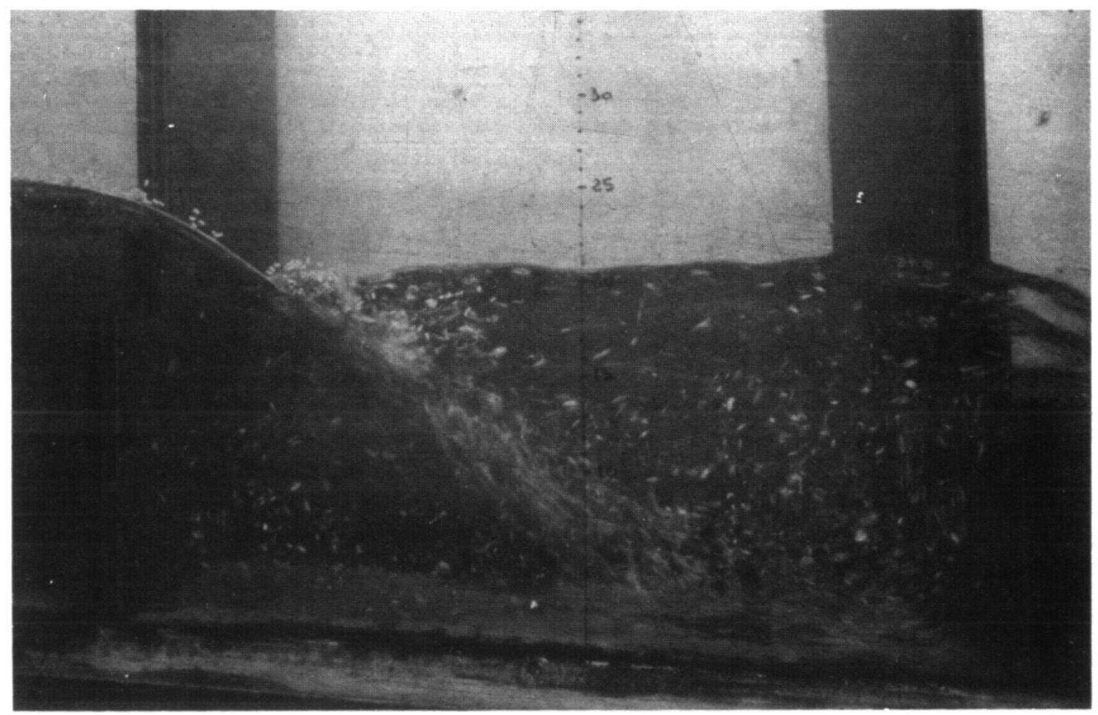

Photo 10 : Visualisation sur modèle réduit de l'écoulement dans une passe à échancrures latérales. Le jet plonge vers le fond du bassin, entraînant la formation d'un " ressaut", ou "retour" on surface. Cotte configuration à jet plongeant est à éviter pour l'alose. Lorsque le niveau d'eau dans la passe augmente, les échancrures sont progressivement noyées par l'aval et le jet passe en surface. 

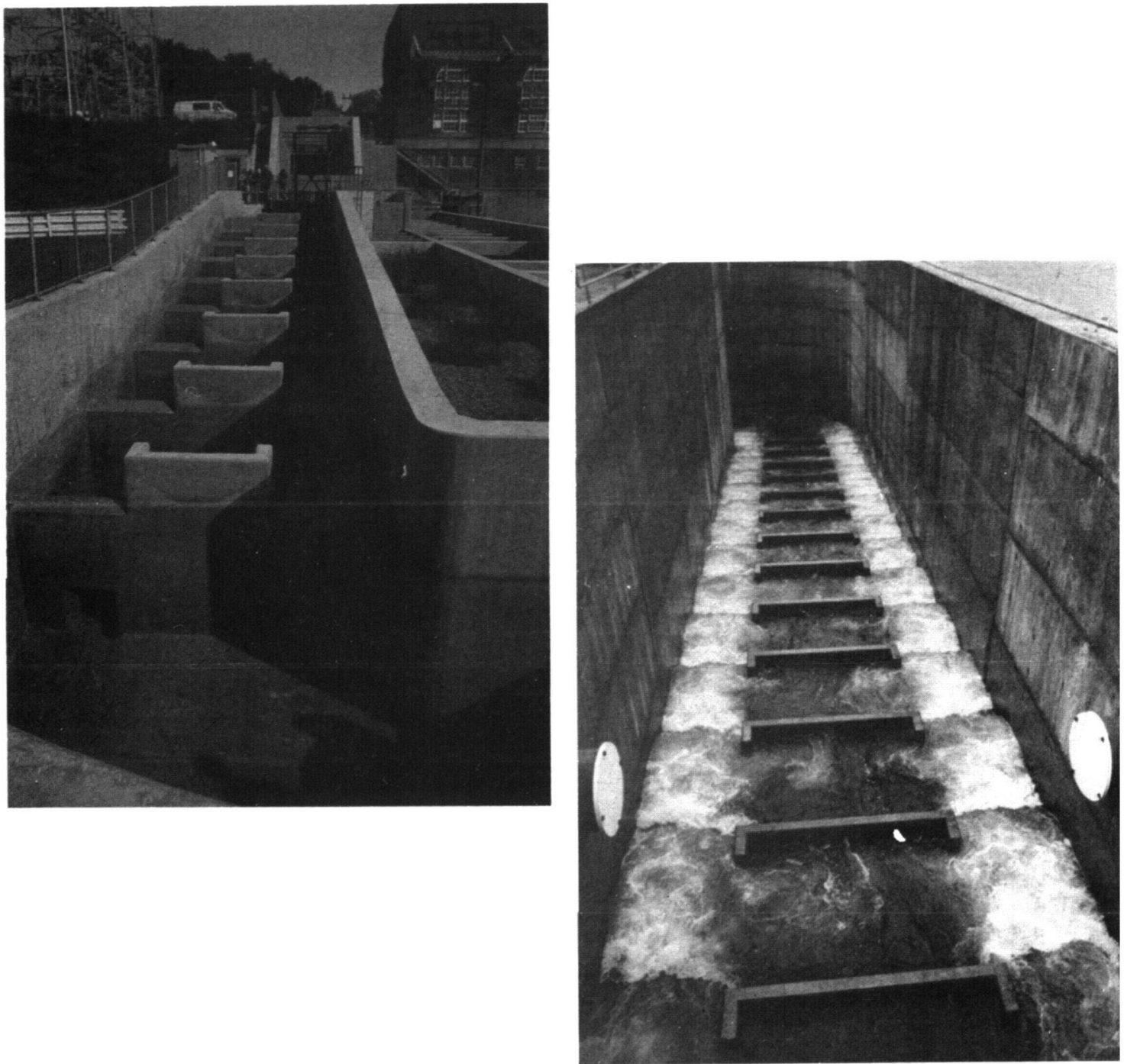

Photos 11 et 12: Passes à bassins successifs mixtes à échancrures latérales déversantes et orifices noyés type "Ice Harbor".

Photo 11 : Barrage de VERNON (rivière Connecticut - Côte Est des EtatsUnis).

Photo 12 : Barrage de BONNEVILLE (rivière Columbia-Côte Ouest des ÉtatsUnis).

La dénivellation entre deux bassins est de $0,30 \mathrm{~m}$, la longueur des bassins de $3.05 \mathrm{~m}$, la hauteur de la partie déversante des cloisons de $1,83 \mathrm{~m}$. La largeur de ce type de passe très souvent utilisé aux États-Unis est très variable et fonction de l'importance du cours d'eau et des populations des espèces migratrices (varie de moins de $2 \mathrm{~m}$ à près de $7.50 \mathrm{~m}$ ). 


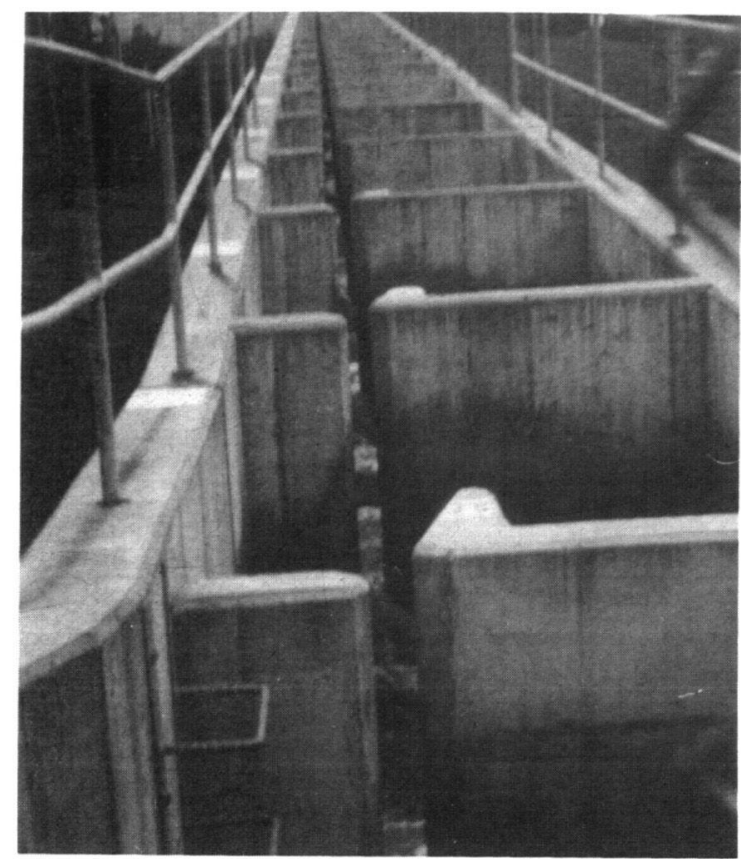

Photo 13 : Passe à fentes verticales. Barrage de RAINBOW. (rivière FARMINGTON, Côte Est des États-Unis). La largeur et la longueur des bassins sont respectivement de $2,1 \mathrm{~m}$ et $3,05 \mathrm{~m}$. La dénivellation entre 2 bassins est de $0,30 \mathrm{~m}$. La largeur de la fente est de $0,25 \mathrm{~m}$. Si l'efficacité de cette passe paraît bonne pour le saumon, elle semble jusqu'à présent très médiocre pour l'alose ; des mortalités importantes ont en effet été constatées pour cette espèce, mortalités attribuées à la turbulence trop forte dans les bassins ainsi qu'à l'étroitesse des fentes (écaillage et blessure des aloses contre les parois lors de leurs allées et venues dans la passe).

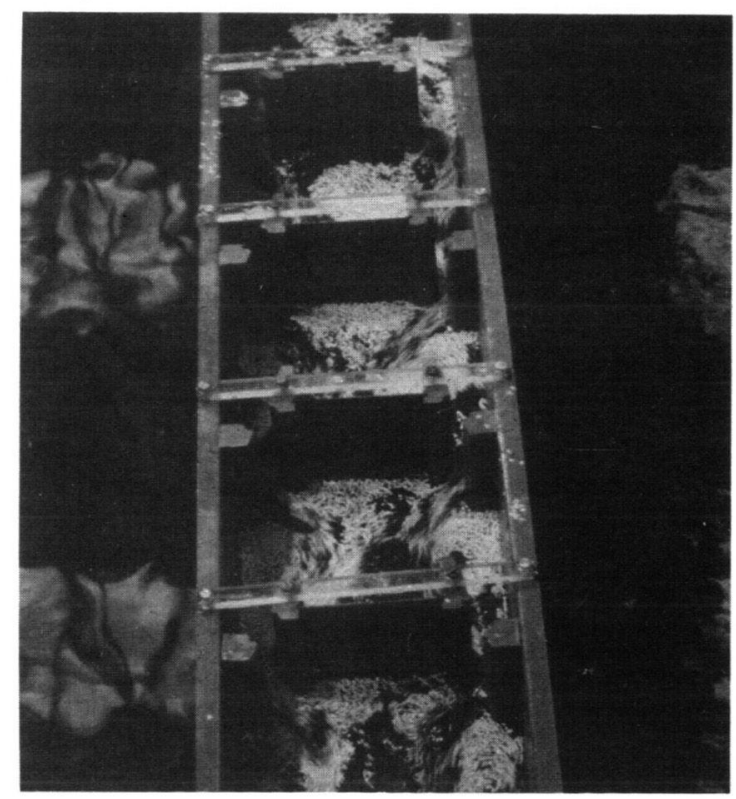

Photo 14 : Visualisation sur modèle réduit de l'écoulement dans une passe à deux fentes verticales (Seuil de BELLEVILLE sur la Loire). La largeur des fentes est de $0,60 \mathrm{~m}$, la longueur et la largeur des bassins sont respectivement de 4,40 et $5,00 \mathrm{~m}$. 


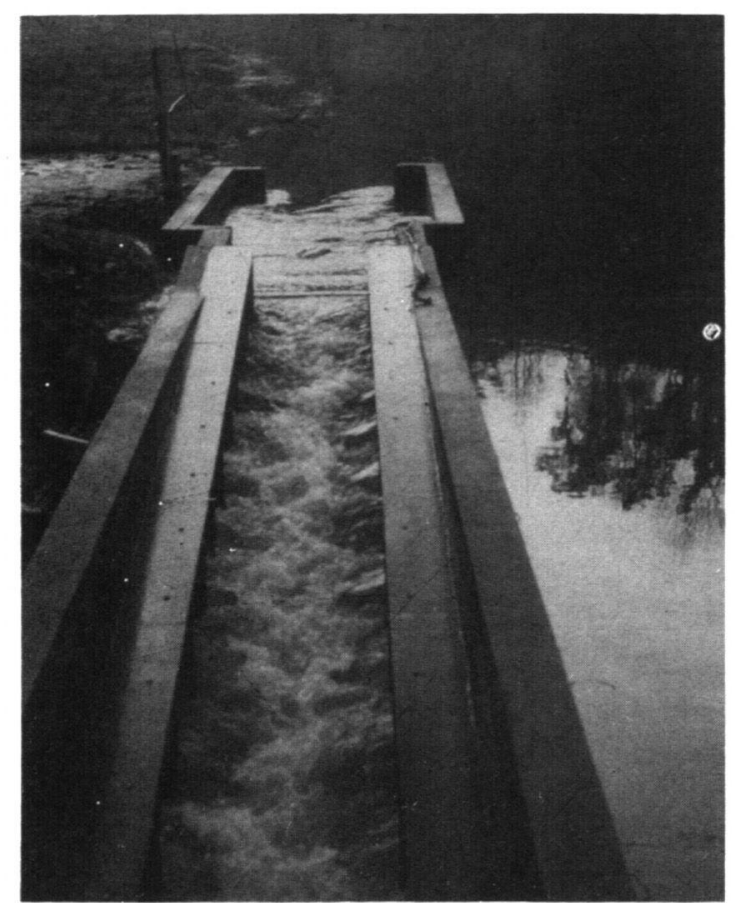

Photo 15 : Passe à ralentisseurs de type "FATOU" au Moulin de la Mothe sur I'ELLE (Finistère)

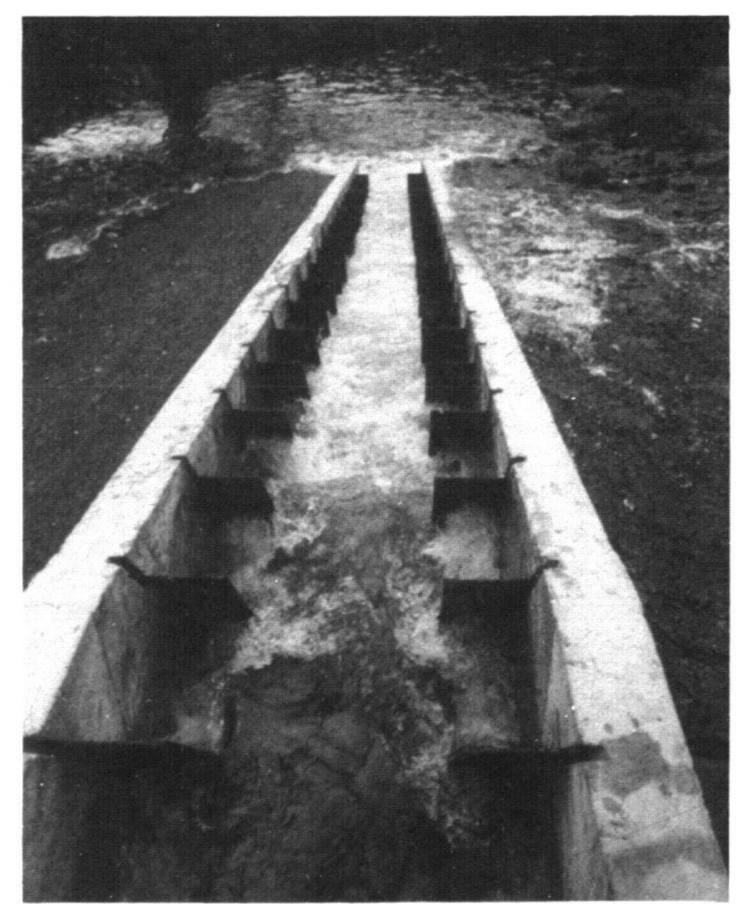

Photo 16 : Passe à ralentisseurs plans sur l'EVEL (Morbihan).

De nombreuses passes à ralentisseurs de ce type ont été installées en Bretagne et Basse Normandie pour assurer le franchissement des obstacles par les salmonidés migrateurs. Les largeurs sont généralement de $0,80 \mathrm{~m}$ (débit $200 \mathrm{I} / \mathrm{s}$ ) ou $0,90 \mathrm{~m}$ (débit $300 \mathrm{l} / \mathrm{s}$ ), exceptionnellement de $1,20 \mathrm{~m}$, les pentes varient de 15 à $20 \%$, la longueur maximale des volées étant de $12 \mathrm{~m}$. 


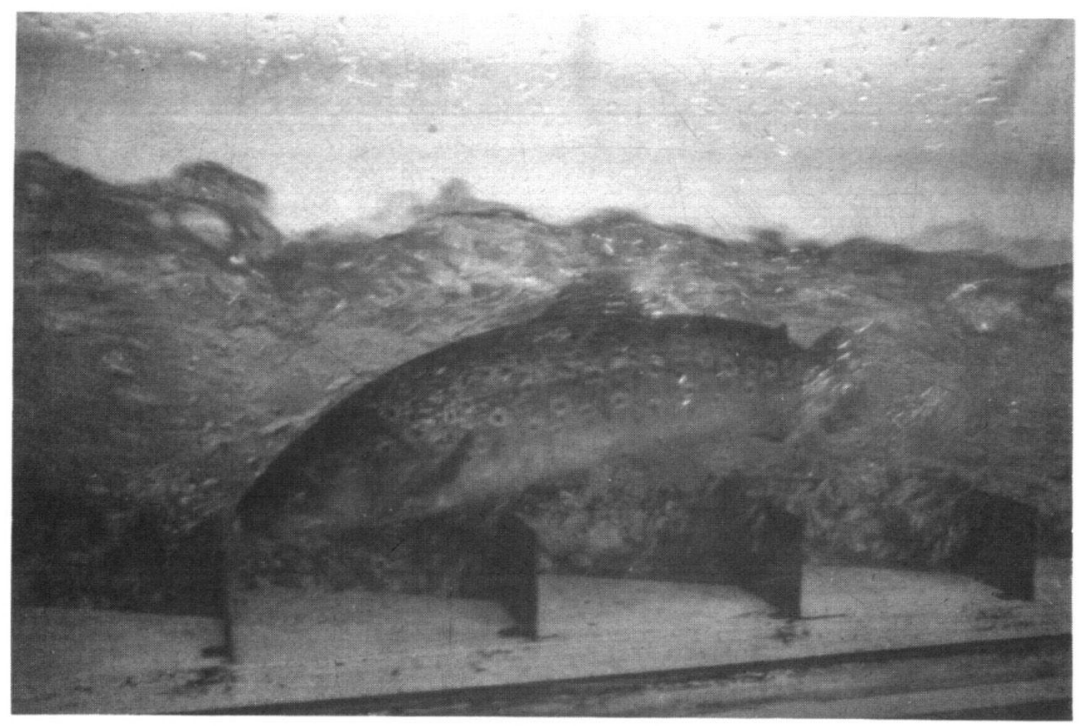

Photo 17 : Truite remontant un canal équipé de ralentisseurs de fond suractifs.

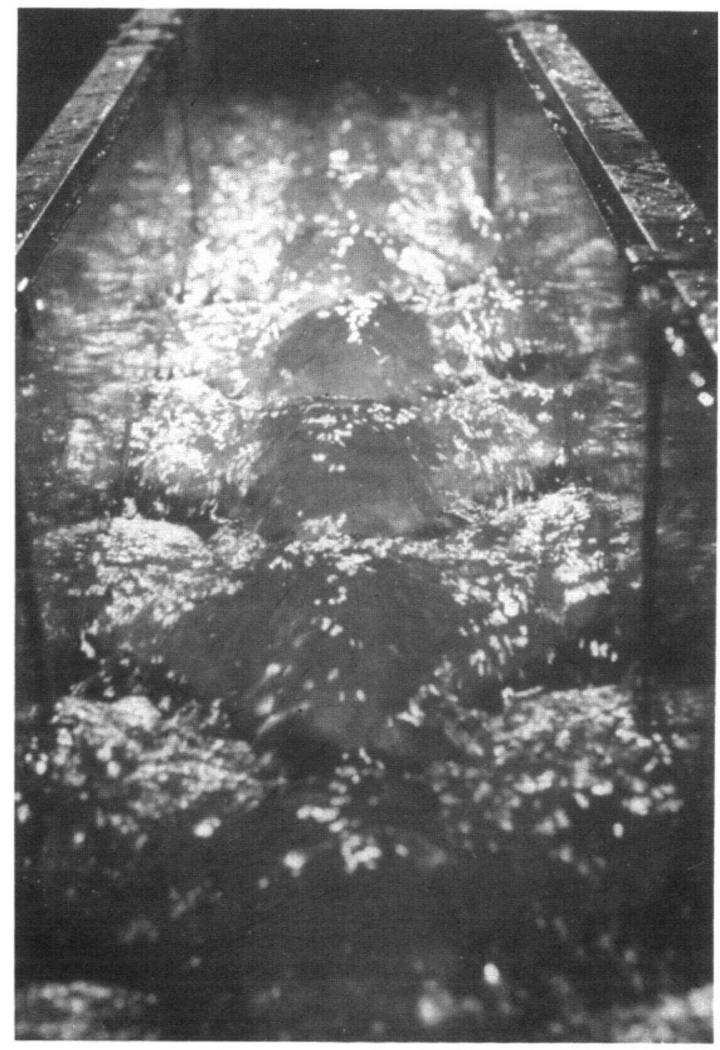

Photo 18 : Écoulement dans une passe à ralentisseurs de fond en chevrons épais (pointe vers l'aval). Ce type de passe, avec deux bandes de ralentisseurs juxtaposées, peut être utilisé comme glissière à canoë-kayak. 


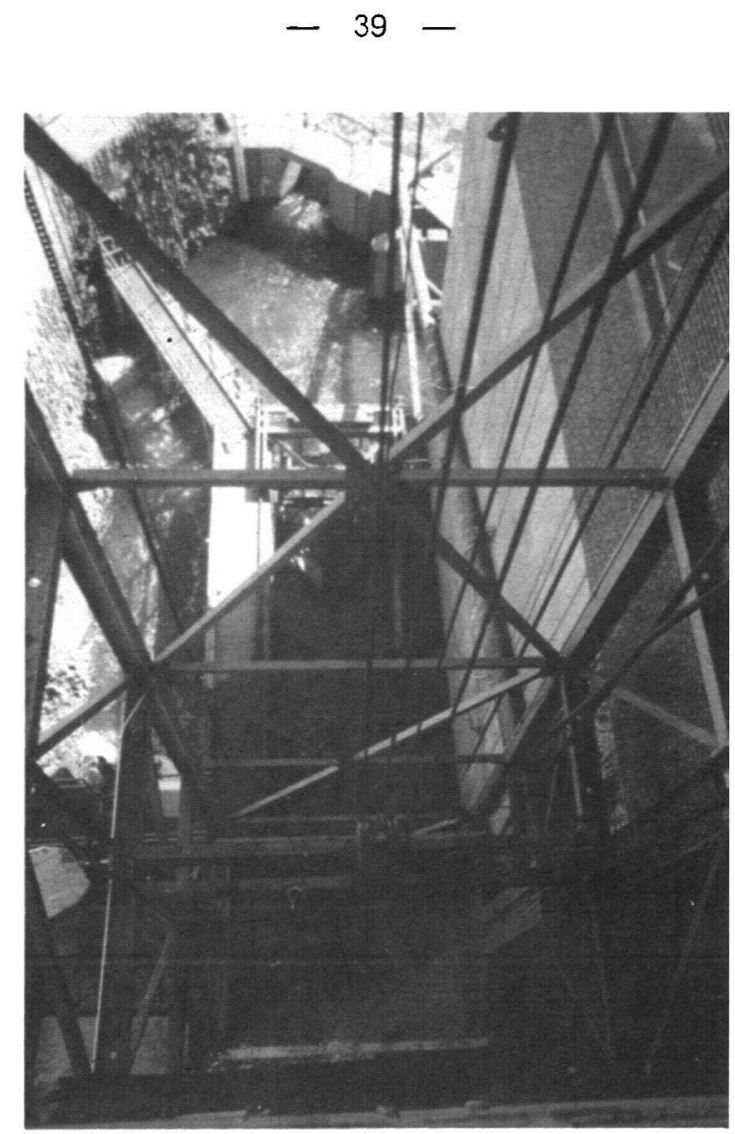

Photo 19 : Ascenseur d'HOLYOKE sur la rivière CONNECTICUT (Côte Est des États-Unis). Au premier plan, la superstructure de l'ascenseur avec la cuve (volume: $6,3 \mathrm{~m}^{3}$ ) ; en haut, l'entrée principale donnant dans le canal de fuite de l'usine. A gauche, l'arrivée du débit d'attrait. Au centre, le bassin de stabulation avec la grille montée sur charriot mobile en position de piégeage. Cet ascenseur permet le franchissement du barrage par 300.000 à 400.000 aloses.

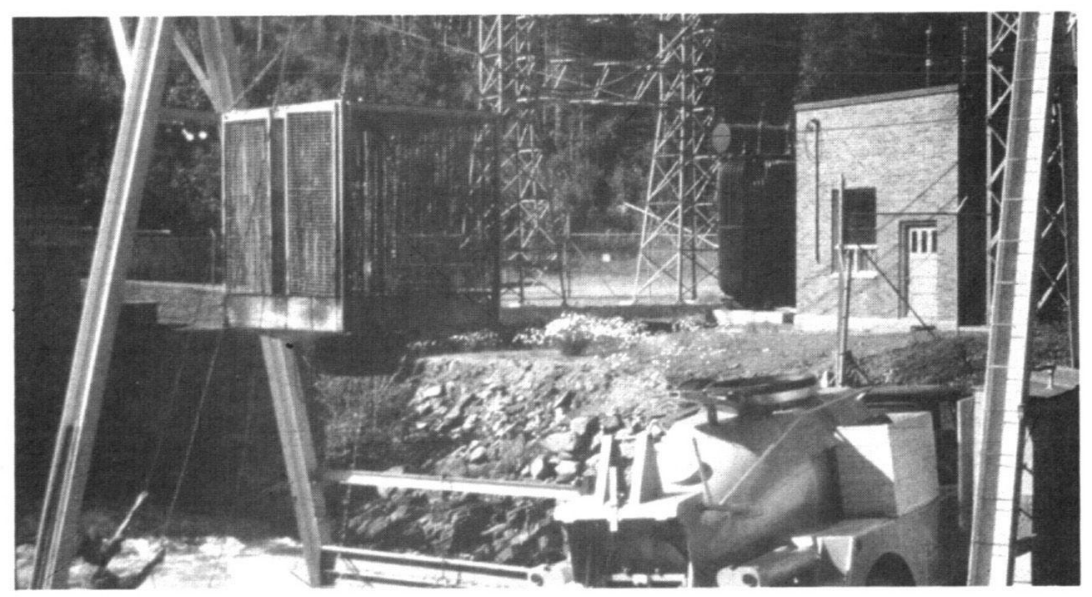

Photo 20 : Dispositif de capture et de transport par camion sur la rivière METIS (Québec - CANADA). Une grille située dans le canal de fuite de l'usine hydroélectrique guide les migrateurs vers un bassin de stabulation. Ceux-ci sont alors poussés à l'aide d'une grille mobile dans la cage en forme de trémie qui est soulevée puis vidée dans la cuve du camion. Cette cuve est déversée dans la rivière une quinzaine de kilomètres en amont, ce qui permet le franchissement de deux aménagements hydroélectriques. 